\title{
History, Chronology and Techno-Typology of the Upper Paleolithic Sequence in the Shuidonggou Area, Northern China
}

\author{
Feng $\mathrm{Li}^{1,2,3}$ (D) Steven L. Kuhn ${ }^{4}$ Ofer Bar-Yosef ${ }^{5}$. Fu-you Chen ${ }^{1,2} \cdot$ Fei Peng $^{1,2}$. \\ Xing $\mathrm{Gao}^{1,2,6}$
}

Published online: 22 May 2019

(c) The Author(s) 2019

\begin{abstract}
The timing and behavioral markers of the Upper Paleolithic in different parts of the world are of great importance to research on modern human dispersals. The pattern of behavioral developments in the Upper Paleolithic in northern China differs in important ways from the patterns observed in West Eurasia, Africa, and South Asia. Shuidonggou (SDG), a cluster of Paleolithic sites in northern China, contains several of the most important Upper Paleolithic sites in the region. Various localities yield evidence of three major cultural components dated by ${ }^{14} \mathrm{C}$, uranium-series, and optically stimulated luminescence (OSL) methods to between roughly $46 \mathrm{ka}$ and $10 \mathrm{ka}$. The oldest component, blade assemblages with western Eurasian early Upper Paleolithic characteristics, appears to be intrusive from Siberia and/or Mongolia, beginning at least $41 \mathrm{ka}$ (e.g., SDG 1 and SDG 9). Advanced core and flake assemblages may mark the appearance of an indigenous Late Paleolithic of North China beginning at around $33 \mathrm{ka}$ (e.g., SDG 2 and SDG 8). Finally, around $10.5 \mathrm{ka}$, microblade technology arrived in the area (SDG 12), although we are not sure of its origins at present. Other typical Upper Paleolithic cultural remains, such as bone tools and body decorations, have been found at various localities in the SDG area as well (e.g., ostrich eggshell beads from SDG 2, 7, and 8). Information from this cluster of occupations increases our understanding of cultural variability, adaptation, and demographic dynamics of modern humans in Late Pleistocene northern Asia.
\end{abstract}

Keywords Shuidonggou · Chronology · Techno-typology · Late Pleistocene · Northern China

Feng Li

lifeng@ivpp.ac.cn

Extended author information available on the last page of the article 


\section{Introduction}

Documenting the chronology and material cultural markers of Upper Paleolithic $(\sim 45 \mathrm{ka}$ to $10 \mathrm{ka})$ assemblages in different geographic regions is vital for understanding population dispersals and technological diffusion, cultural diversity, and the behavioral adaptive strategies of Pleistocene modern humans (Homo sapiens). In Europe, West Asia, and Africa, chronological sequences of Upper Paleolithic (UP) or Late Stone Age (LSA) industries, including many regional 'cultures' are well established. In general, the beginning of the UP is represented by blade and bladelet production, bone tools, proliferation of personal ornaments, and occasionally mobile and parietal art (e.g., Bar-Yosef 1998, 2002, 2006; Conard 2003; Klein 2009). In South Asia, Late Paleolithic assemblages with blade and microblade production, and, more rarely, symbolic objects, were present beginning 35-30 ka (James and Petraglia 2005; Petraglia, Haslam, Fuller, Boivin and Clarkson 2010). However, expedient lithic technology without systematic blade or bladelet manufacture dominated in the contemporaneous period in Sahul (Habgood and Franklin 2008). In East Asia, the diversity of cultural entities seems to be greater. Blade assemblages with western Eurasian UP features and various expedient non-laminar, core and flake assemblages were present in different regions, especially in north Asia (Bar-Yosef and Wang 2012; Li, Kuhn, Olsen, Chen and Gao 2014; Li, Chen, Wang and Gao 2016; Qu, Bar-Yosef, Wang and Wu 2013).

Beginning in the early Pleistocene, simple core and flake assemblages dominated the Chinese Paleolithic record (Bar-Yosef and Wang 2012; Gao 2013). In northern China these technologies persisted until the terminal Pleistocene, and in southern China into the early Holocene, a time when various sophisticated lithic technologies prevailed in other regions of Eurasia. The persistence of simple lithic technologies along with human fossils bearing mosaic morphological characteristics of Homo erectus and Homo sapiens during the later Middle Pleistocene, as at Dali (Athreya and Wu 2017; Wu and Athreya 2013), Jinniushan (Chen, Yang and $\mathrm{Wu}$ 1994), and Lingjing ( $\mathrm{Li}, \mathrm{Z}$. et al. 2017), have been considered as evidence supporting an in situ evolution of modern human groups in China ( $\mathrm{Li}$ and Gao 2018; Gao 2013; Wu and Xu 2016). At the same time, blade assemblages demonstrating western Eurasian UP features generally associated with modern humans appeared in regions of northwestern China, such as Xinjiang, Ningxia, and Inner Mongolia, about $40 \mathrm{ka}$ ( $\mathrm{Li}$, Kuhn et al. 2014). Although no fossils have been found associated with these UP blade assemblages in northern China, modern humans occupied these regions at roughly the same time, as indicated by the early Homo sapiens fossils discovered at Tianyuandong (Shang, Tong, Zhang, Chen and Trinkaus 2007) and the Upper Cave (Li, Bae, Ramsey, Chen and Gao 2018) of the Zhoukoudian site complex. Thereafter, blade assemblages co-existed with simple flake assemblages from approximately $40 \mathrm{ka}$ to $30 \mathrm{ka}$ in northern China. And beginning about $25 \mathrm{ka}$, microblade assemblages arose and spread widely in northern China shortly after the Last Glacial Maximum (LGM). The various lithic assemblages of the later Late Pleistocene in northern China demonstrate 
a complex picture of the Upper Paleolithic and probably of modern human dispersals across the region, which has not been appropriately addressed. The Shuidonggou (SDG) area (c. $10 \mathrm{~km}^{2}$ ) in northern China contains multiple Paleolithic sites with a range of assemblage types dating to between around $45 \mathrm{ka}$ and $10 \mathrm{ka}$, including flake, blade, and microblade assemblages. The area plays an essential role in understanding the development and origins of the Upper Paleolithic in northern China.

Discovered in 1923, the Shuidonggou site cluster is often equated with Locality 1 , the first site to be discovered and excavated. Shuidonggou has been interpreted in terms of large-scale diffusion of the European Upper Paleolithic, based mainly on the large blade assemblage found at SDG Locality 1 (Boule, Breuil, Licent and Teilhard de Chardin 1928; Brantingham, Kaivoshapkin, Li and Tserendagva 2001; Madsen et al. 2001). However, a wide range of assemblages with different technologies and ages have been identified through subsequent research in the area (Gao, Wang, Pei and Chen 2013b; Li, Gao et al. 2013; Pei et al. 2012). Although numerous reports of the recent field operations and laboratory studies of SDG localities 1-5, 7, 8, 9, and 12 have been published (Boëda, Hou, Forestier, Sarel and Wang 2013; Gao et al. 2008; Gao, Wang and Guan 2013a; Li, Kuhn, Gao and Chen 2013; Liu et al. 2009; Morgan et al. 2014; Nian, Gao and Zhou 2014; Pei et al. 2012; Yi, Chen, Pei and Gao 2014; Wang, Pei, Ma and Feng 2007, and references therein), the chronology of major localities continues to be debated (e.g., Keates and Kuzmin 2015; Li, Kuhn et al. 2013; Li, Kuhn and Gao 2015). More importantly, the technological characteristics and chronology of the various archaeological layers and localities are difficult to extract from the available literature, while some older publications are even misleading. In this paper we summarize the general cultural features of the various archaeological layers within the dated Upper Paleolithic or late Paleolithic localities in the Shuidonggou area. A critical review of the chronology at various localities helps to resolve some of the fundamental ambiguities about the ages of and relationships between the various components. A review of the techno-typological characteristics of assemblages found in the Shuidonggou area further expands our understanding of cultural variability, adaptation, and demographic dynamics of modern humans in Late Pleistocene northern China.

\section{Setting of the Shuidonggou Site Cluster}

The Shuidonggou area is located in the Ningxia Hui Autonomous Region of northern China, $18 \mathrm{~km}$ east of the Yellow River on the margins of the Mu Us Desert (Fig. 1). The region lies in an arid to semi-arid transition zone, which is strongly seasonal and has a continental climate, dominated by the winter monsoon. The modern Biangou River flowing from the southeast into the Yellow River cut the river terraces through the area in which the buried Paleolithic localities are exposed (Fig. 2).

The Paleolithic site cluster at Shuidonggou was first located and investigated by French paleontologists Émile Licent and Pierre Teilhard de Chardin in 1923 (Licent and Teilhard de Chardin 1925). They initially recorded five distinct localities (F1-F5, now SDG 1-5) in the Shuidonggou valley, and excavated an area of around 


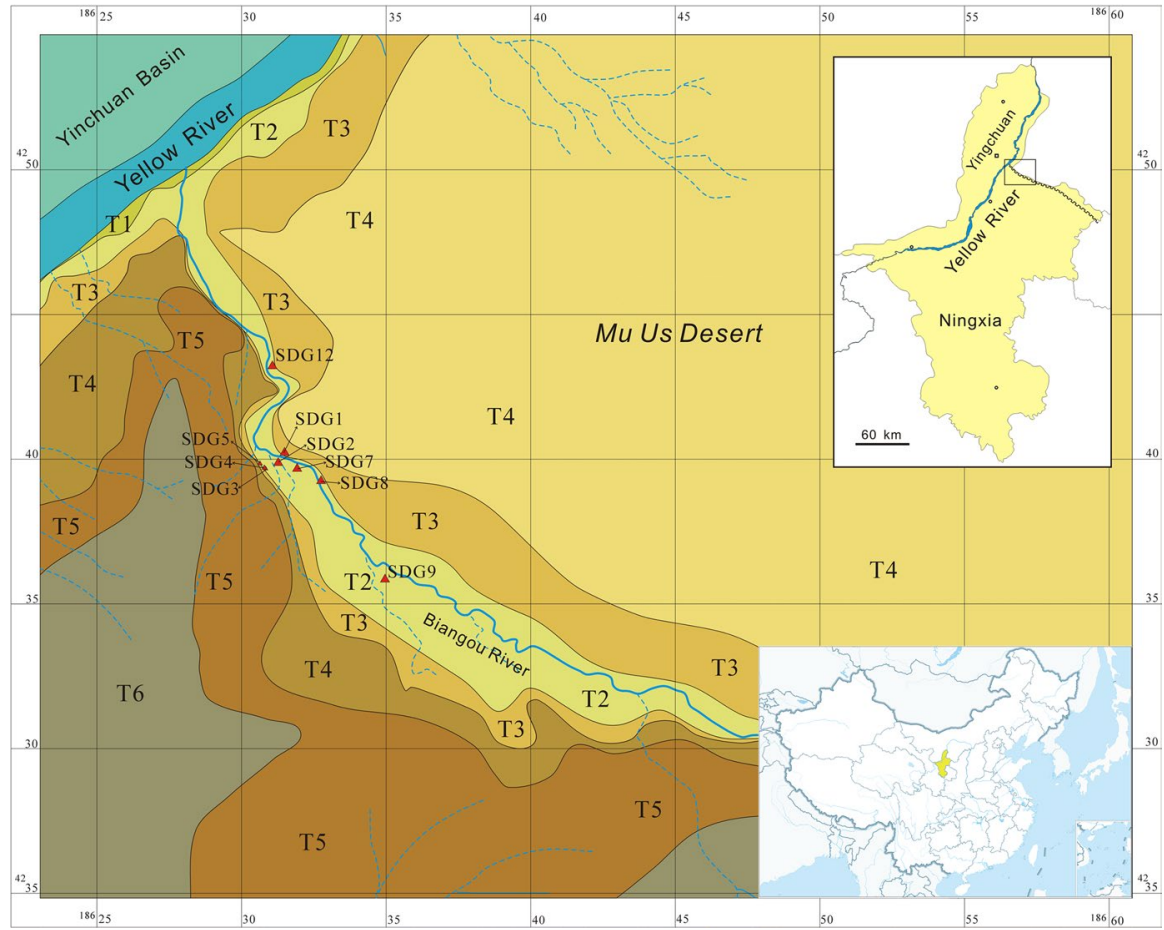

Fig. 1 Location and geomorphology of the Shuidonggou area showing Terraces 1-6, and the excavated Paleolithic localities (SDG 1-5, 7-9, and 12). Modified after Liu (2008)

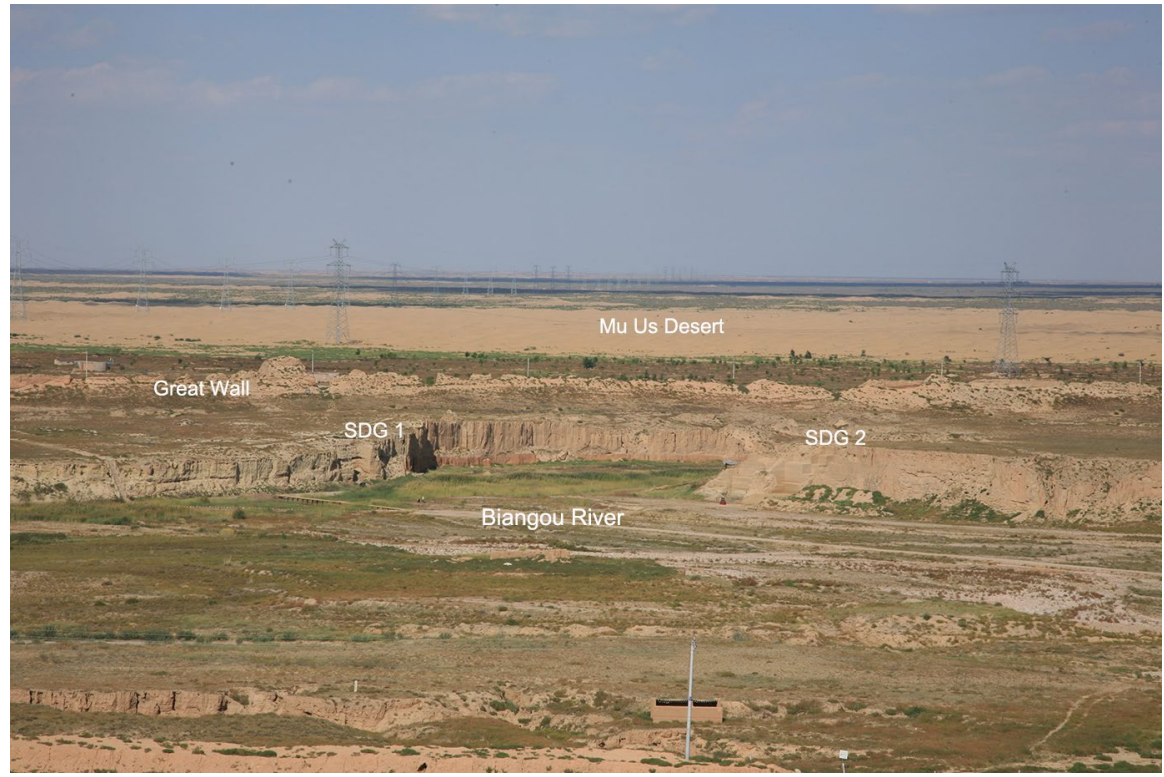

Fig. 2 Landscape at SDG 1 and SDG 2 
$80 \mathrm{~m}^{2}$ at Locality 1 . Locality 1 was re-excavated and studied intensively in several later campaigns (Jia, Gai and Li 1964; Ningxia Museum, Ningxia Bureau of Geology, Chu Cheng Geological Research Team 1987). During the 1963 excavations at Locality 1 a surface site named as Xiaokouzi (SDG 6), $500 \mathrm{~m}$ northwest of locality 1, was also investigated (Zhang 1999). A new research program has been underway at Shuidonggou since 2002. This most recent program of research resulted in discovery of another six Paleolithic localities (SDG 7-12) (Gao, Pei, Wang and Zhong 2004; Liu et al. 2008). Beginning in 2003, seven localities, 2-5, 7-9, and 12, were systematically excavated as part of this new project (see Pei et al. 2012 and Gao, Wang, Pei and Chen $2013 \mathrm{~b}$ for a review of the recent excavations).

Six geomorphological terraces have been identified in the SDG region (Fig. 1). Terraces 6-3 are mainly gravel and sandy deposits of foothill fluvial fans. Terraces 2 and 1 consist of fluvial and lacustrine or wetland deposit. Terrace 2, $15 \mathrm{~m}$ above the bed of the modern Biangou River, is the most widely distributed terrace in the Shuidonggou area (Fig. 2), and buries all the Paleolithic localities except the surface locality SDG 6 (Liu et al. 2009). As a pedestal terrace, it is characterized by a clear dual structure, with poorly-sorted gravel in the lower part and multi-band peat and lacustrine accumulation in the upper part (see Liu et al. 2009, 2012 for details). The Shuidonggou area is a roughly rectangular depression facing the Yellow River to the northwest. Geomorphological survey conducted by Dr. Liu demonstrates that a fault forms an elevated platform between the Yellow River and the Shuidonggou area (Liu 2008). This high ground could have blocked the local river, causing a lake and wetlands to develop in the area after the formation of Terrace 3. Detailed grain size and pollen analyses of the sections of SDG localities 1, 2, and 7 led to a fourstage model of the depositional environment within the area at the time Terrace 2 was developing. The lowest part of the sequence consists of riverine gravel and sand deposits. This gives way successively to a swamp with numerous aquatic plants, then a shallow lake deposit. Finally the marginal bank depositional conditions deteriorated and the desert steppe environment formed (Liu et al. 2012).

As of this writing, eight of the 12 SDG localities (SDG 1-5, 7-9, and 12) have been excavated. No direct dates are available at SDG localities 3-5. For this reason, we focus on the excavated localities 1, 2, 7-9, and 12. Various dating methods including accelerator mass spectrometry (AMS), optically stimulated luminescence (OSL), and uranium-series (U-series) were applied by different laboratories. Published dates from layers with Paleolithic material are listed in Table 1. In general, the OSL dates from the SDG sites produced in the luminescence lab of the Institute of Earth Environment of the Chinese Academy of Sciences (IEE) seem problematic. The age-depth correlation of those OSL dates at Localities 1, 2, 9, and 12 is weak (Liu et al. 2008, 2009, 2012), and the OSL ages are almost always more recent than both stratigraphically-associated AMS ${ }^{14} \mathrm{C}$ dates (SDG 2) and OSL dates (SDG 1) produced in other labs (Li, Gao et al. 2013; Li, Kuhn et al. 2013; Nian, Gao and Zhou 2014). Noting the uncertainty of the dates from IEE lab, we rely more on the OSL dates produced in the Peking University lab and the AMS ${ }^{14} \mathrm{C}$ dates. The reliability of the ${ }^{14} \mathrm{C}$ dates was evaluated following the strategy proposed by Pettitt, Davies, Gamble and Richards (2003) and Graf (2009). Seven criteria were considered, including sample type, measurement and lab reporting, association with 


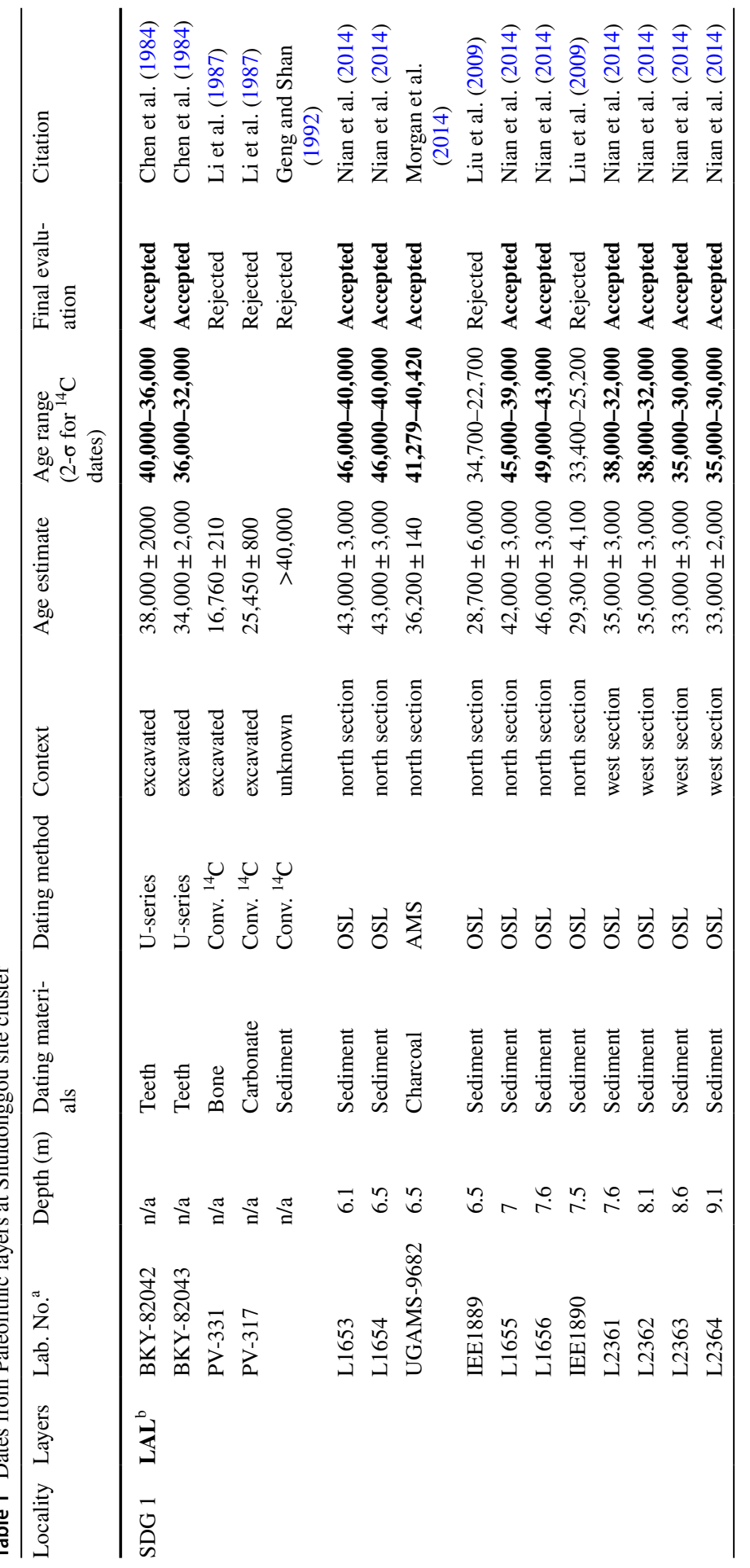




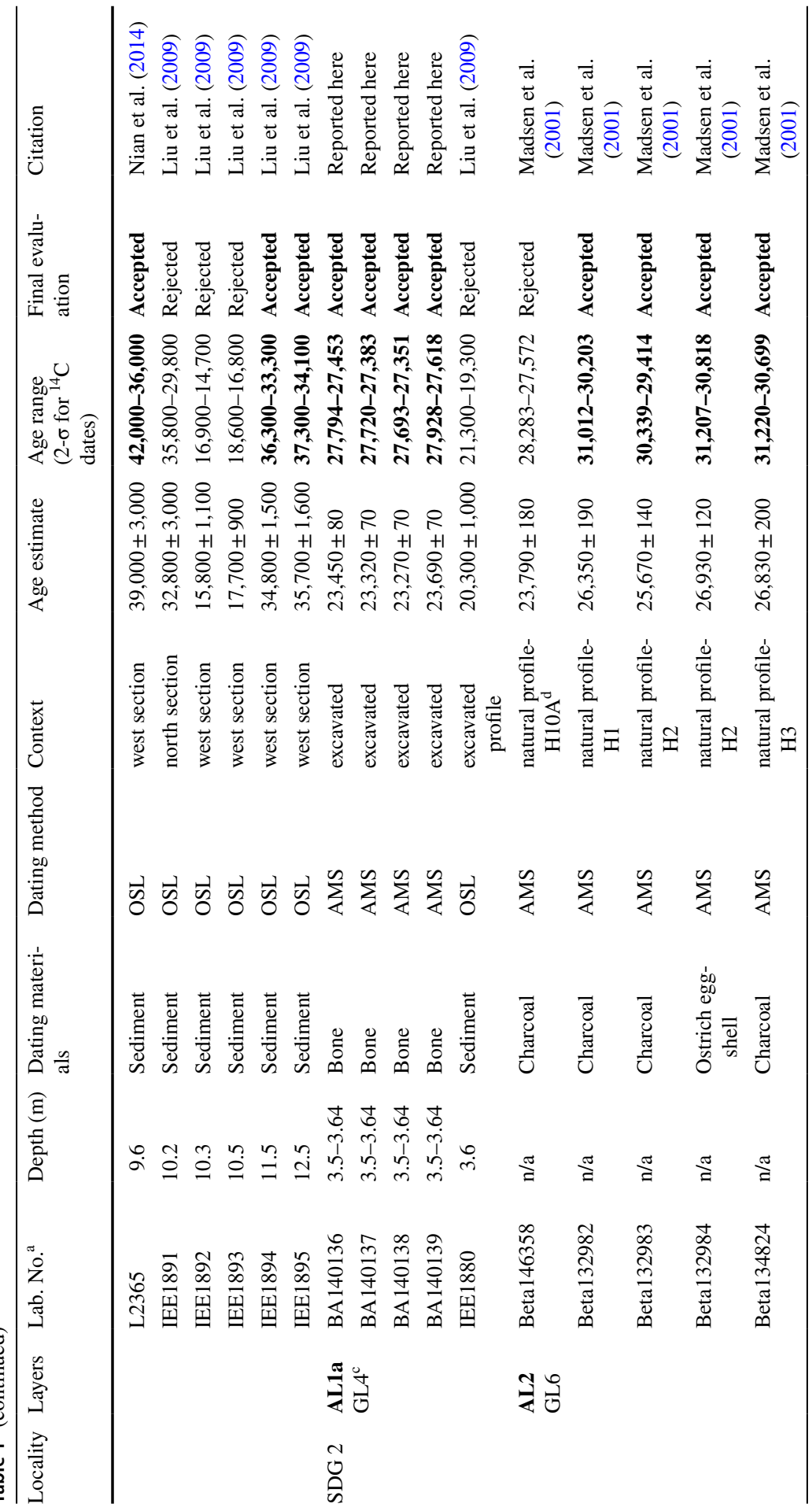




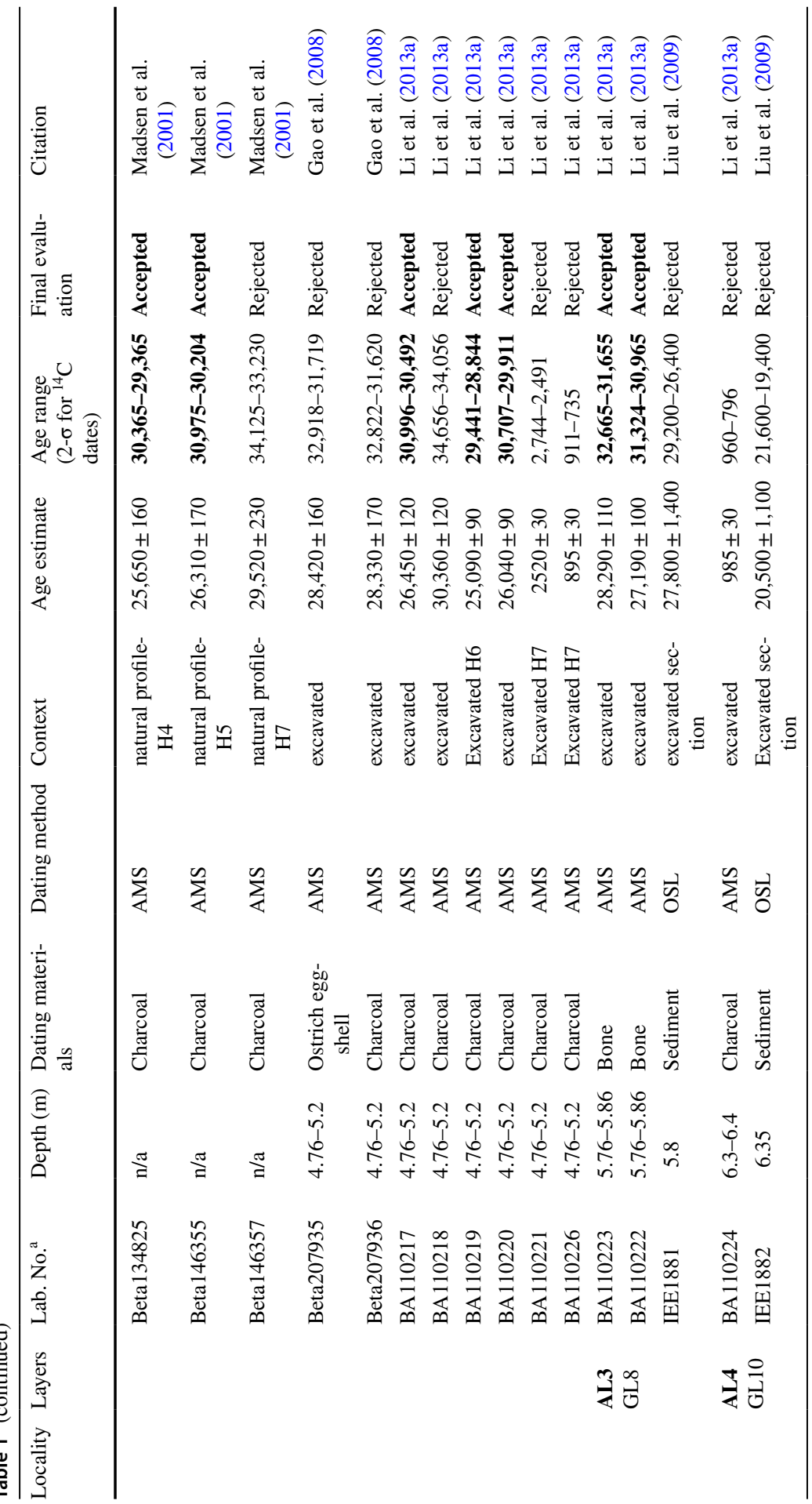




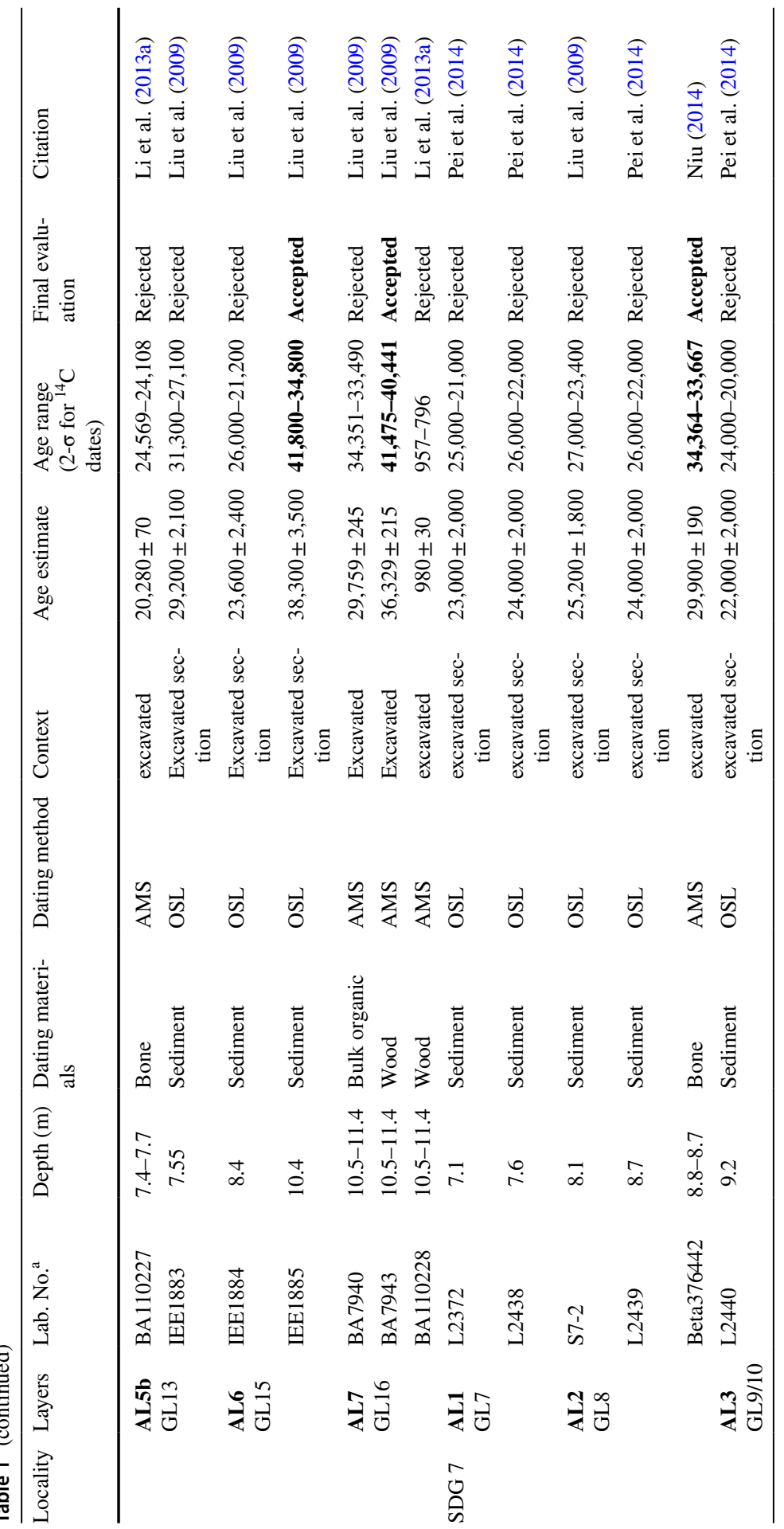




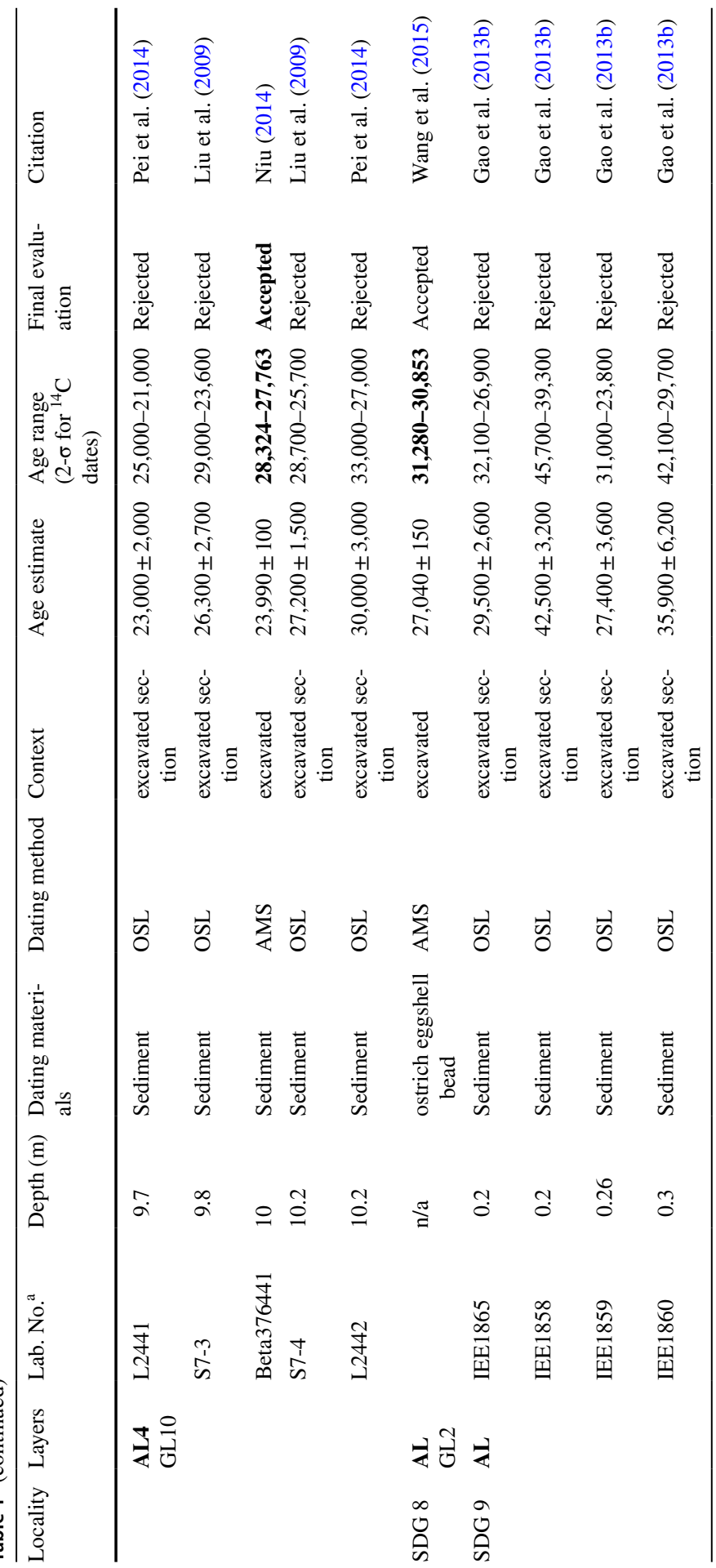




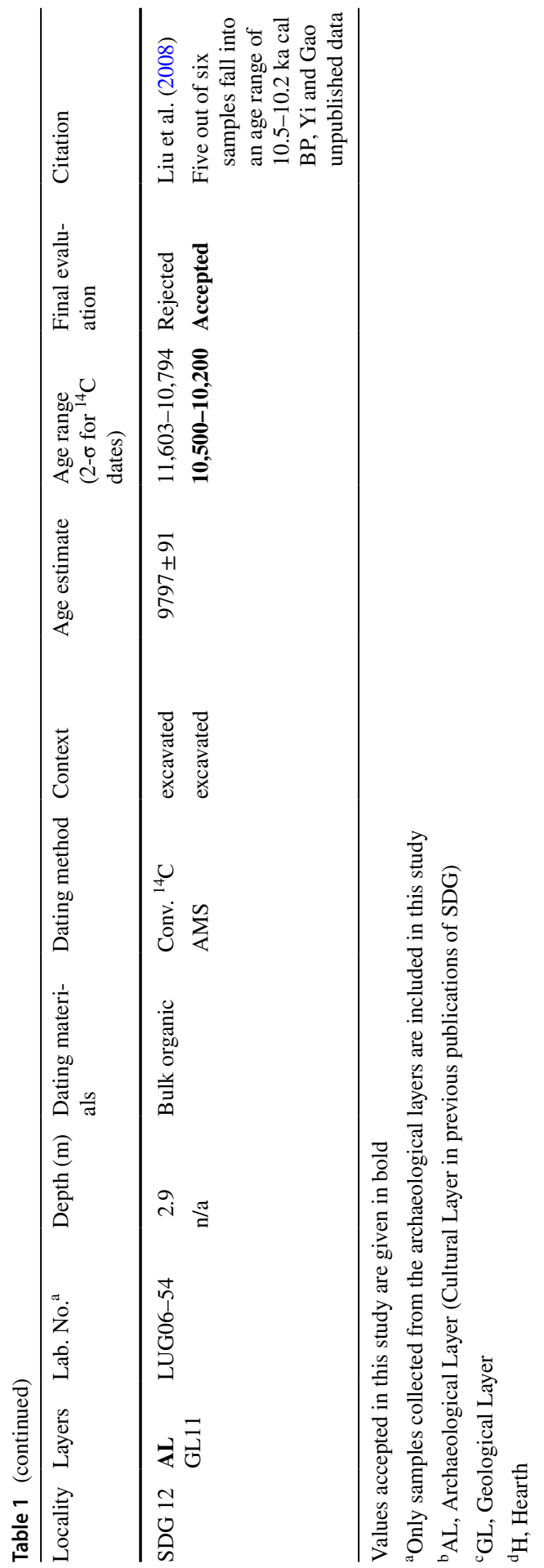


archaeology, relevance of dating samples to a specific diagnostic archaeological phenomenon, quantity of age estimates, error ranges, and stratigraphic context. The OSL and U-series dates were accepted either if they were consistent with the ${ }^{14} \mathrm{C}$ dates, or if they show good age-depth correlations on their own.

\section{Chronology and Techno-Typology of the SDG Paleolithic Sites}

\section{SDG 1}

Following the first excavations in 1923, Locality 1 was re-excavated in 1960, 1963 and 1980 (Licent and Teilhard de Chardin 1925; Jia, Gai and Li 1964; Ningxia Museum, Ningxia Bureau of Geology, Chu Cheng Geological Research Team 1987). The locations of the archaeological materials within the stratigraphy were not well recorded in the early excavations: at best, items were assigned to very thick layers. Subsequent geological studies, including dating programs, were conducted independently of the archaeological investigations. Thus, it can be difficult to securely relate the archaeological findings to the different dated depositional layers at SDG 1.

The stratigraphic sequence at SDG 1 is usually divided into two parts, the Late Pleistocene (lower cultural layer) and Holocene (upper cultural layer) deposits (Fig. 3). Taking account of the relatively crude association of the archaeological materials and stratigraphy, tentative age estimates of c. 20-30 ka for lower cultural layer A, and 34-38 ka for lower cultural layer B have been suggested, based on the previous radiocarbon and U-series dates (Li, Kuhn et al. 2013). More recently, earlier ages for the Paleolithic sequence of this locality have also been suggested,

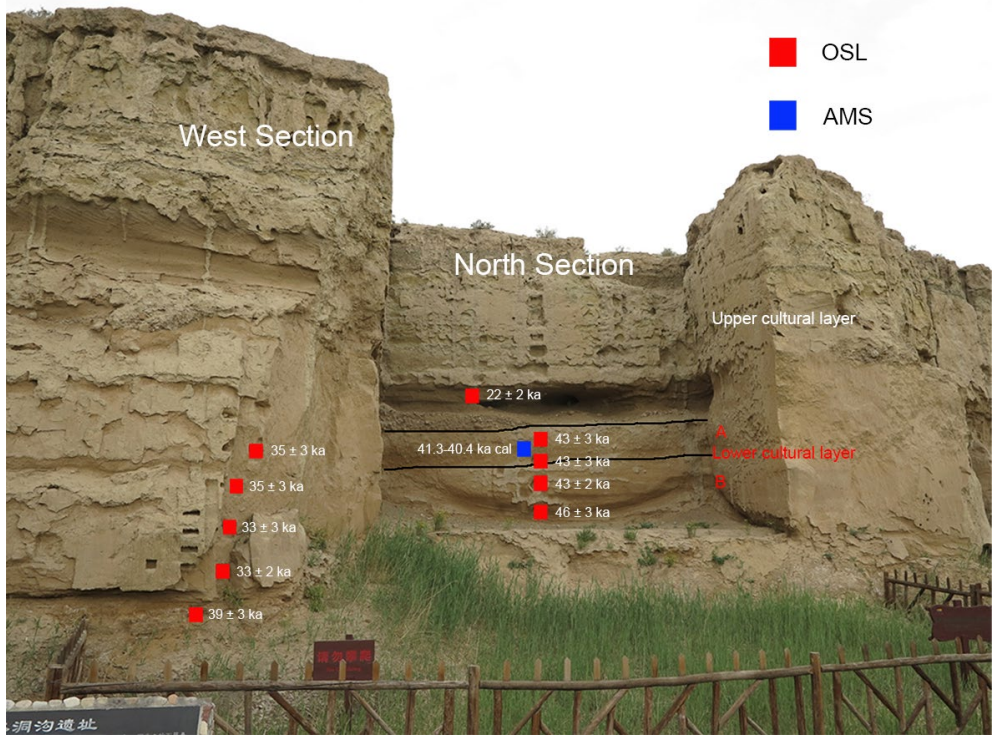

Fig. 3 Sections and dates of SDG 1 
including a date of $\sim 41 \mathrm{ka}$ cal BP based on a single charcoal sample (Morgan et al. 2014), and a range of 33-46 ka from more systematic OSL analysis (Nian, Gao and Zhou 2014). The new OSL dates reveal two sets of ages at SDG 1. Samples from the North Section of the exposed 1980 excavation trench indicate an age range of 49-39 ka, whereas OSL dates from the West Section indicate an age range of 41-30 ka (Fig. 3). The AMS date best fits the OSL age of the North Section, where it was collected. The two chronological sequences raise the possibility that different parts of the SDG 1 Paleolithic deposit lying at the same elevation formed at different times (Li, Kuhn and Gao 2015). This would imply either that some post-depositional disturbance occurred, or that there are unrecognized cut-and-fill events in the sequence. The new excavation, ongoing since 2018, will clarify the stratigraphic and chronological issues at this locality, but it is clear that the age of the large blade assemblage from the Late Pleistocene layers is older than some investigators have previously stated (Madsen et al. 2001; Keates and Kuzmin 2015).

The archaeological remains from the lower cultural layers A and B at SDG 1 were collected and reported as a single assemblage. It is possible, even likely, that different lithic complexes (blade and core and flake) from multiple archaeological layers are present in the $5 \mathrm{~m}$-thick stratum ( $\mathrm{Li}$, Kuhn et al. 2013). However, the majority of the material collected from the lower cultural layers is representative of a bladebased technology. The often-described lithic assemblage from the lower cultural layer at SDG 1 was the product of systematic Levallois and prismatic blade reduction. Two independent studies of the lithic artifact sample from the 1980 excavation have been conducted and their results agree closely (See Brantingham et al. 2001 and Peng, Wang and Gao 2014 for details). Most of the cores produced blades or elongated flakes, and nearly $30 \%$ of the products are blades. Retouched tools include various scrapers, denticulates, and notches. Both flakes and blades were retouched; points and endscrapers were most often made on blades.

\section{SDG 2}

Locality 2 was found in 1923. It is situated directly across the Biangou River from SDG 1. Before the river was downcut the two site areas could have been part of the same land surface. An area of $100 \mathrm{~m}^{2}$ was excavated at SDG 2 in 2003-2005 and 2007. From 2014 to 2016, a new trench of $30 \mathrm{~m}^{2}$ was excavated (Peng et al. 2017, 2018). The stratigraphic sequence, with a total thickness of $12.5 \mathrm{~m}$, contains 18 layers, seven of which yielded Paleolithic remains. Layers with archaeological remains were referred to as cultural layers (CL) in previous publications (e.g., Li, Gao et al. 2013; Li, Kuhn et al. 2013). However, considering that a layer with archaeological remains could represent a geological as well as an anthropogenic accumulation, the term archaeological layer (AL) is more appropriate. AL1 to AL7 were named from the top to the bottom through the sequence, with two pairs of subdivisions in AL1 (1a and 1b) and AL5 (5a and 5b) (Fig. 4).

A total of 29 dates have published from Locality 2, including AMS ${ }^{14} \mathrm{C}$ and OSL dates, and some controversies concerning the ages remain (Keates and Kuzmin 2015; Li, Kuhn and Gao 2015). Here we summarize the dating results and also report four 


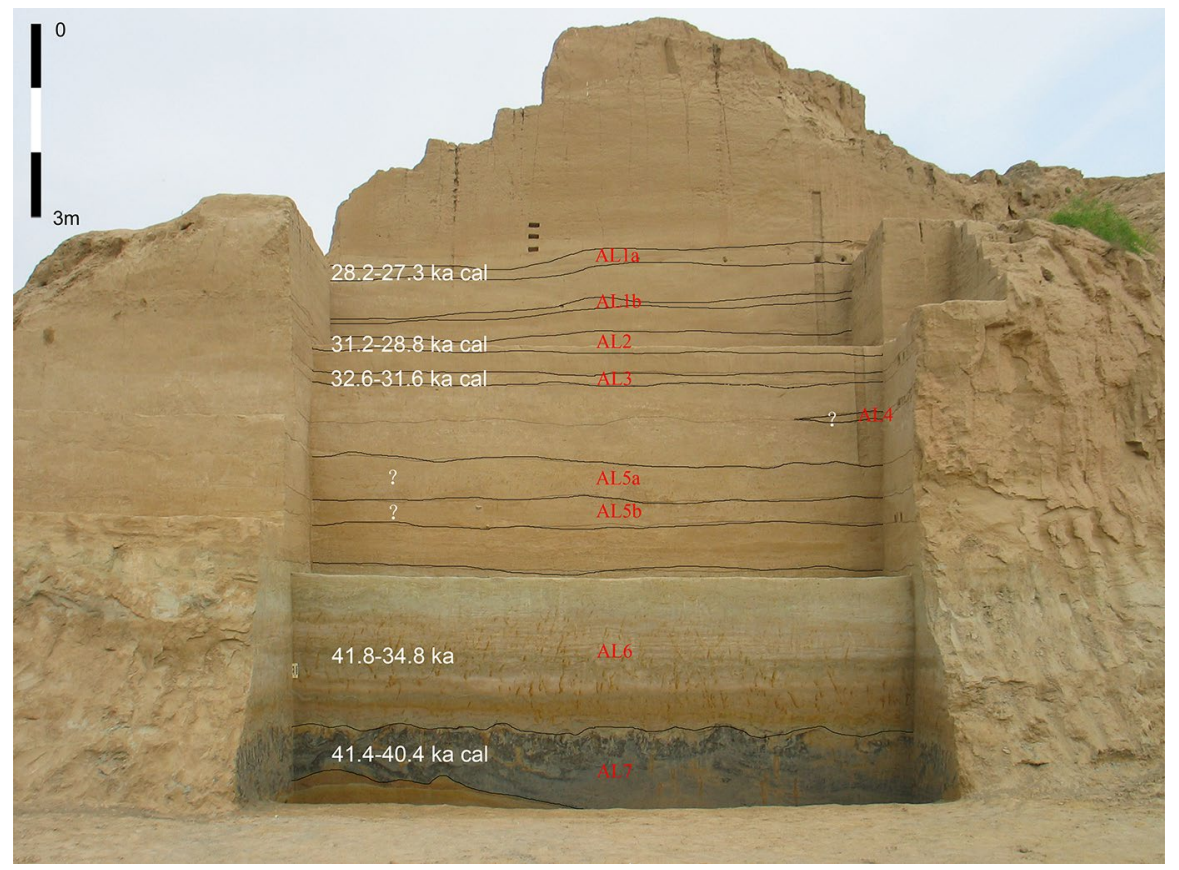

Fig. 4 Stratigraphy and archaeological layers of SDG 2. Modified after Li, Gao et al. (2013)

new dates from AL1a at SDG 2. Of the 33 readings, four are obviously of much too recent age and were considered invalid (BA 110221, 110224, 110226, and 110228). AL1a and AL2 at locality 2 were intensively dated and most of the dates are consistent. Four AMS ${ }^{14} \mathrm{C}$ determinations date AL1a to around $27 \mathrm{ka}$ cal BP. Three in situ samples provide an age estimate for AL2 of c. 29,441-30,996 yr cal BP. Previous to the excavations at SDG 2 a series of ${ }^{14} \mathrm{C}$ dates were run on charcoal samples collected from the naturally eroded section (Madsen et al. 2001). Based on depth and contextual information they should probably be attributed to AL2 (Gao et al. 2008; Li, Gao et al. 2013). As we are not certain exactly how the dates published by Madsen et al. (2001) relate to the excavated archaeological layers we have accepted the dates (6 out of 10) that overlap with the ages of in situ samples of AL2, and rejected the others. Two dates from AL3 fall into a range of 32,665-30,965 yr cal BP, which overlaps with the age of AL2. Dates from AL4 and AL5 do not fit the stratigraphic context and have been rejected. Although most of the OSL dates from IEE lab were considered problematic, one of the OSL dates (IEE1885, 38.3 $\pm 3.5 \mathrm{ka}$ ) from AL6 fits the AMS sequence. One of two AMS dates from AL7 fits the stratigraphic context: the age is 41,475-40,441 yr cal BP.

Lithic assemblages from the different archaeological layers at SDG 2 can be divided into two broad groups (see Li, Kuhn et al. 2013 for details). AL7 and AL5a yielded two blade cores similar to the ones described from SDG 1. The assemblages from AL6, AL5b, and AL4-AL1 show consistent features, which include comparatively simple flake production and side-scraper-dominated tool 
assemblages. These core and flake assemblages contain no evidence for systematic production of blades or Levallois elements. However, some technological changes and other innovations are documented within the sequence of core and flake assemblages in AL5b and AL4-AL1. AL2 is especially important in this respect: in addition to the lithics manufactured from river pebbles, some artifacts made of high quality chert with unrolled cortex were also discovered. Investigations along the Biangou River valley show pebble raw materials are easily found on the river beaches (Fig. 2) and old terrace gravel deposits near the site (Li, Kuhn, Chen and Gao 2016; Lin et al. 2018). However, the fine chert was not found near the site. Rather, these materials must have come from a primary source (or from somewhere close to a primary source), based upon the fresh cortex preserved on some artifacts. Although sources of this high quality material have not been identified so far, we would expect them to be more than $5 \mathrm{~km}$ from the site according to our survey (Li, Kuhn et al. 2016). Soft-hammer percussion might have been used for the reduction of this material (Li, Kuhn et al. 2016). Small, bladelet-sized blanks manufactured on high quality material were also present, although few counterpart cores were found. AL1a shows a high frequency of bipolar reduction on small, local high-quality chert pebbles, and as a result small elongated blanks are much more common than in other layers. Well-retouched endscrapers mainly on flakes are present in assemblages from AL2 and AL1a but not in earlier layers. One fragment of a grinding tool was discovered in AL1a.

Hearths surrounded by abundant charcoal, lithics, faunal remains, and ornaments have been identified in several archaeological layers at SDG2 (Fig. 5). Based upon the pattern of hearths and artifact distribution, SDG 2 was argued to be a base camp of ancient foragers (Guan, Gao, Wang et al. 2011; Guan, Gao, Li et al. 2012). Ornaments and bone tools are present in AL3 and AL2: one freshwater shell bead fragment was found in AL3 (Wei, d'Errico, Vanhaeren, Li, and Gao 2016), and more than 70 ostrich eggshell beads and a bone needle fragment were collected from AL2 (Li, Chen and Gao 2014; Martí, Wei, Gao, Chen and d'Errico 2017). Studies of starch grains, phytoliths and plant tissue fragments on
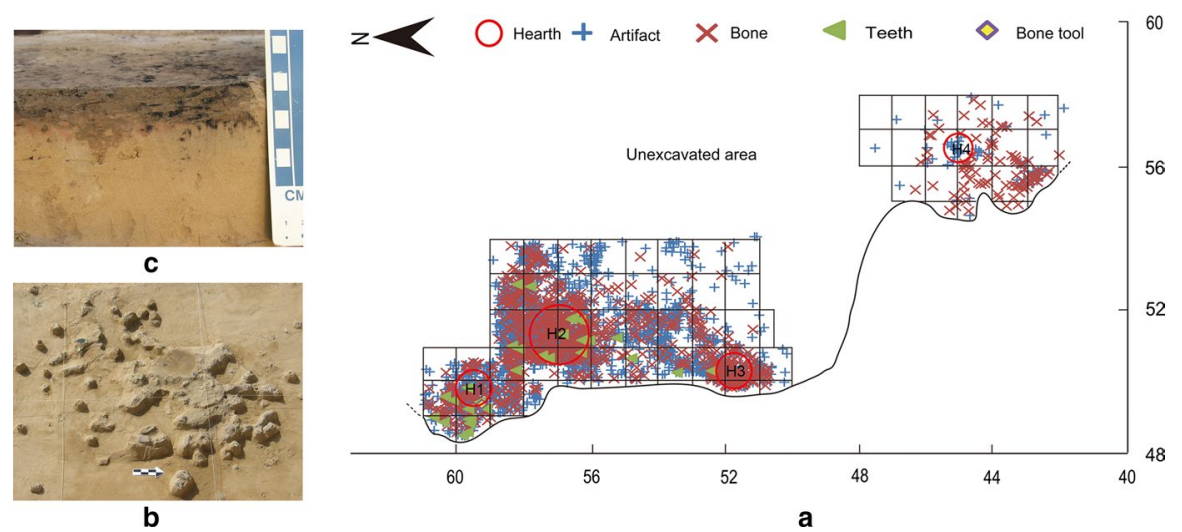

Fig. 5 Plan distribution of hearths of AL2 at SDG2. Adapted after Li, Chen and Gao (2014) 
the artifacts from AL1-3 at SDG 2 provide direct evidence of plant use activities during late MIS 3 (Guan, Gao et al. 2012; Guan, Pearsall et al. 2014).

\section{SDG 7}

Locality 7 was found in 2002, and a trench of $25 \mathrm{~m}^{2}$ was excavated from 2003 to 2005. The exposed strata reached a total thickness of $12 \mathrm{~m}$, and 11 depositional layers were identified, four of which contain archaeological materials (Fig. 6). OSL and AMS dates were obtained, but the age-depth correlation of these dates is not strong (Liu et al. 2009; Niu et al. 2016). The OSL dates from nearly the entire archaeological sequence, with a total thickness of $3.8 \mathrm{~m}$, are almost identical (22-24 ka), and such rapid sediment accumulation seems to contradict the findings from other sites in the area such as SDG 2. In addition, the AMS dates of bones are consistently older than the OSL dates. This may indicate that the archaeological materials were produced earlier but the sequence was disturbed during a short period, which resulted in the uniformity of sediment age of nearly the whole archeological sequence. Although debitage size distribution suggests that the technological composition of this assemblage is relatively intact (Pei et al. 2014), geological observation and artifact distribution show this site was reworked by hydraulic processes (Niu et al. 2016) (Fig. 6). As a result, the dates of the sediments may not represent the age of human occupations. Consequently all the OSL dates from this locality were rejected. The two AMS dates, 34,364-33,667 and 28,342-27,763 yr cal BP, were accepted as a rough estimate of the age of the archaeological materials at SDG 7.

A large number of lithic items, some faunal remains, and two ostrich eggshell beads were found at SDG 7. Lithic assemblages from Layers 7-11 were studied and reported together, so differentiating technological units from different layers

Fig. 6 Stratigraphy and dates at SDG 7; GL: geological layer. Modified after Pei et al. (2014)

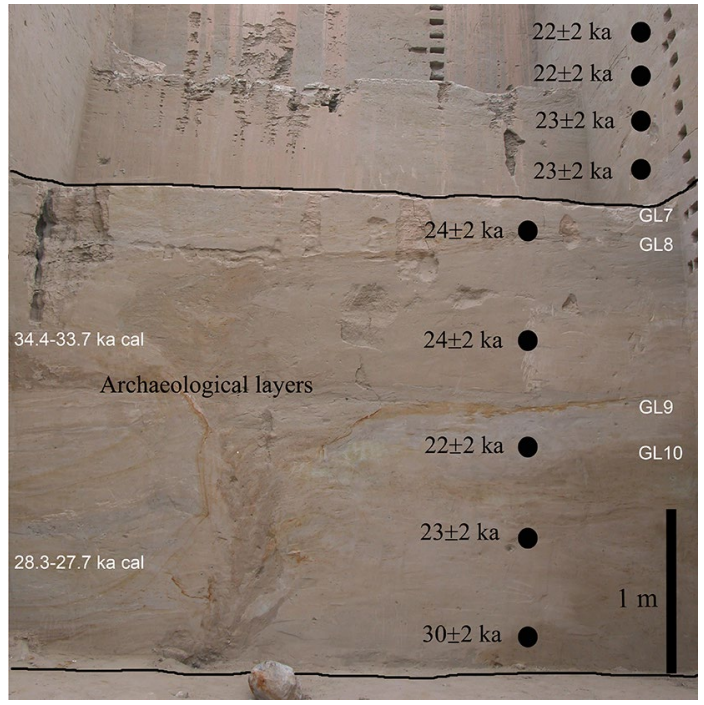


is difficult. The majority of the lithic artifacts were produced from simple singleplatform and multiple-platform flake cores. Modified lithic artifacts include bipolar pieces, a few well-made endscrapers, and lightly retouched sidescrapers. Although a blade component is represented by eight flat-faced blade cores from the lower archaeological deposits (Niu et al. 2016), it is hard to determine its age and relationship with the core and flake industry due to the uncertainty of the stratigraphy. The mixed context of the assemblage makes a clear-cut description of technological units at SDG 7 extremely difficult. However, similar lithic artifact types including blade cores, well-made endscrapers, various bipolar products, and ostrich eggshell beads were found at SDG 2, the closest locality. Combined with some overlap in the AMS dates, this opens the possibility that SDG 7 was connected with SDG 2 stratigraphically, but was on the edge of the main occupation area where some postdepositional disturbances occurred.

\section{SDG 8}

Locality 8 was first identified in 2002. A trench of $16 \mathrm{~m}^{2}$ was excavated in 2003. The exposed strata reached a total thickness of $3.5 \mathrm{~m}$, and three depositional layers were identified, but only one (Layer 2), about $0.5 \mathrm{~m}$ thick, contained archaeological remains. An ostrich shell bead fragment yielded an age of 31,280-30,853 yr cal BP. Although this is the only date, it fits well with the age estimate of the archeological layer (AL2) with ostrich eggshell beads at SDG 2, where two ostrich eggshell samples yielded ages of 31,207-30,818 and 32,918-31,719 yr cal BP.

A total of 776 stone artifacts manufactured from chert, quartzite, and dolomite were found at SDG 8, along with eight ostrich eggshell beads, but no faunal remains are preserved (Wang et al. 2015). The lithic assemblage was created through simple flake production with hard hammers. Cores were used exclusively for producing flakes without any intentional preparation on the platforms and the working surfaces. Blanks are usually wide flakes with irregular shape, and there are a few elongated flakes but no blades. The frequency of retouched tools is very low (1\%), and retouched tools are lightly modified. The most abundant retouched tools are sidescrapers, most of which are made on relatively flat flakes.

\section{SDG 9}

Locality 9 was discovered in 2002, and a trench of $20 \mathrm{~m}^{2}$ was excavated in 2007. The exposed strata in the excavation area reached a total thickness of $0.6 \mathrm{~m}$, and a $2.8 \mathrm{~m}$ thick section was cut at the north end of the excavation trench. Three depositional layers were identified: all artifacts were found in Layer 2, with most of the artifacts concentrated in a zone around $20 \mathrm{~cm}$ below the contemporary ground surface (Gao, Wang, Pei and Chen 2013b). A series of OSL dates were obtained at the site, but unfortunately correlation of dates and depth is extremely poor (Gao, Wang, Pei and Chen 2013b). Moreover, considering that most of the lithic artifacts were found on or near the surface, this locality is more like a surface site and the validity of OSL dates from the archaeological layer is questionable. 
The lithic assemblage, which includes 417 stone artifacts, largely resembles the blade assemblage from Locality 1 (Gao, Wang, Pei and Chen 2013b). Silicified dolomite $(93.2 \%)$ is the most common raw material, followed by chert $(3.1 \%)$ and quartzite $(2.2 \%)$. Levallois blade cores, prismatic or edge-facetted cores, and a large proportion of blades ( $45.1 \%$ of the blanks) indicate systematic blade production at the site. Levallois cores for flakes as well as discoid cores are also present, though rare. No retouched pieces were found.

\section{SDG 12}

Locality 12 was discovered in 2005. An area of $12 \mathrm{~m}^{2}$ was exposed in 2007 and a much larger area of around $100 \mathrm{~m}^{2}$ was excavated in 2010 (Fig. 7). Unfortunately, the site was destroyed after the 2010 excavation by the construction of a reservoir. The exposed strata of the 2007 excavation reached a total thickness of $9 \mathrm{~m}$, and 12 depositional layers were identified. A grayish fine sand layer with charcoal (Layer 11) contained archaeological materials. The maximum thickness of Layer 11 is $1.6 \mathrm{~m}$, suggesting prolonged or repeated occupations at the site (Fig. 8). Seven AMS dates from the archaeological layer were obtained, five of which bracket the age of the layer at 10,500-10,200 yr cal BP (Liu et al. 2008; Yi and Gao unpublished data).

More than 20,000 stone artifacts from the 2007 excavation were studied. The assemblage consists mainly of products and byproducts of microblade reduction: additional material from the 2010 excavation is currently being analyzed. Microblades and microblade cores make up $18.3 \%$ of the lithic assemblage. Wedge-shaped microblade cores are the most common form at the site but pyramid and cylindrical

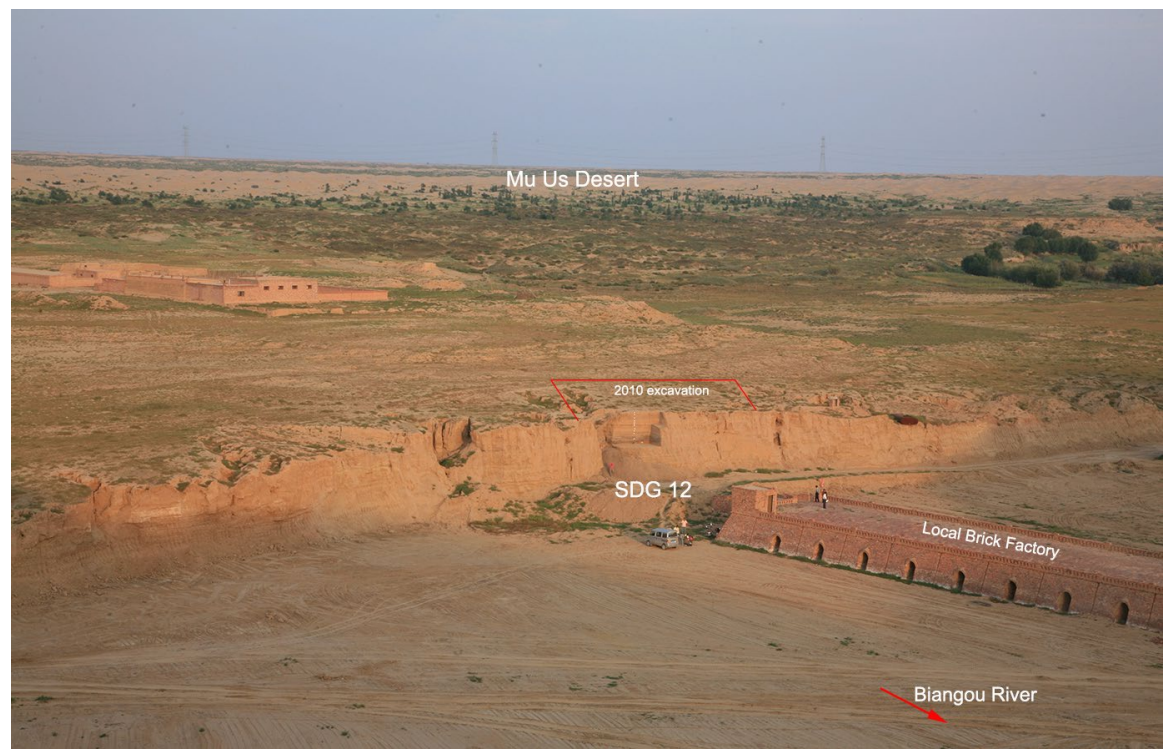

Fig. 7 Landscape at SDG 12 


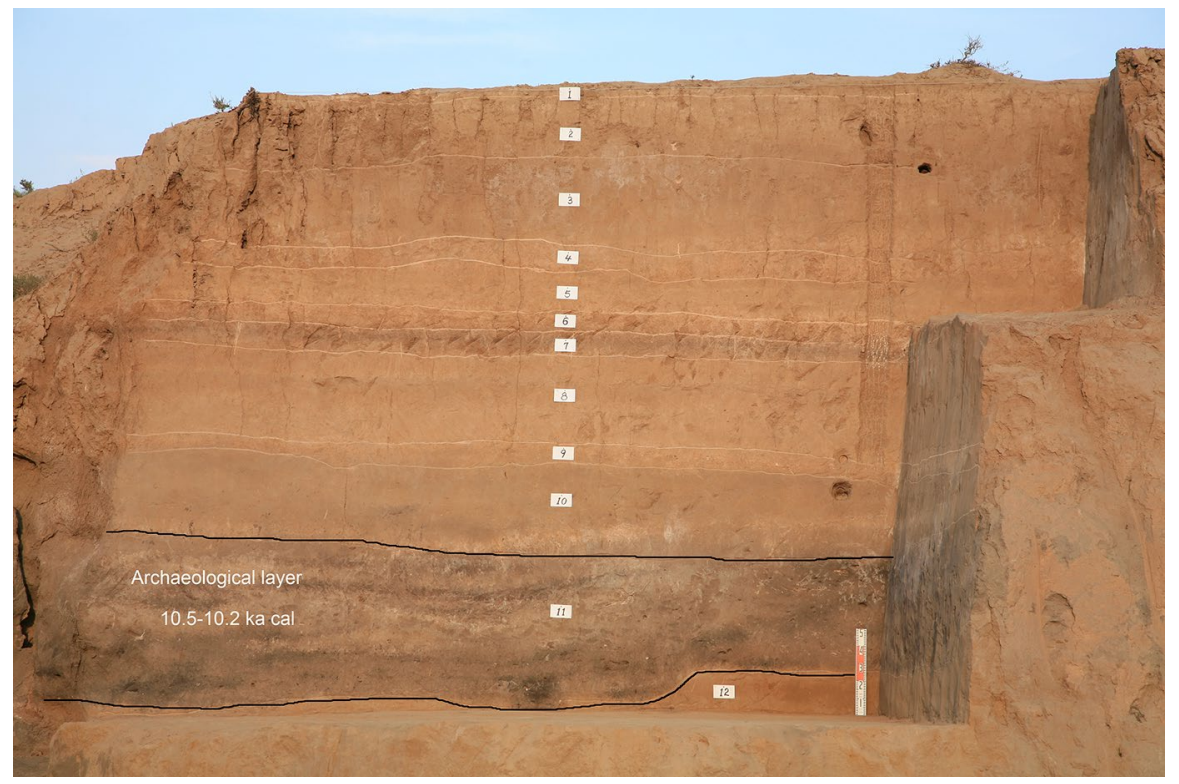

Fig. 8 Stratigraphy and dates at SDG 12 (scale inside is $50 \mathrm{~cm}$ )

core types are also present (Yi, Gao, Wang, Pei and Chen 2015). Based on the wellorganized, regular microblade scars on the working surface of the cores, and punctiform platforms of the microblades, the products were likely obtained by pressure technique. Although blades occur in the assemblage it seems that they were byproducts of preparing the microblade cores and not the targets of reduction. The frequency of retouched tools is low and most of them are irregular rather than formalized. A number of ground stone objects $(n=22)$ was found. These are well-made and functionally diverse. The sample of ground stone items includes a whetstone, a pestle, a milling stone, and a ground axe fragment. Additional finds include a complex bone technology with several distinct types of bone tools (Zhang, Gao et al. 2016; Zhang, Doyon et al. 2018; Yi et al. 2013), as well as ornaments made of calcium nodules.

SDG 12 is one of the best-studied Paleolithic sites of the early Holocene in northern China, and many other topics have been addressed there. Based upon analysis of a large number of broken stones unearthed from the ash layers of SDG 12 and the ecological background at the site, Gao et al. (2014) have suggested that the firecracked rocks were boiling stones used for boiling water and cooking liquid foods. Because the previous age estimate falls into the Younger Dryers (12,900-11,600), several publications have proposed a number of adaptive strategies that could have been adopted by the SDG 12 foragers for cold weather and a harsh environment, including composite microblade toolkits, clothing, grinding tool technology, and sophisticated bone technology (Yi et al. 2013, 2014; Zhang, Doyon et al. 2018). However, with the new series of radiocarbon dates the story of hunter-gatherer adaptation at SDG 12 should be reframed. 


\section{Summary}

In the Shuidonggou area, there are seven groups of radiometric dates: the North Section of SDG 1 and SDG 2-AL7; the West Section of SDG 1; SDG 2-AL6; SDG 2-AL3; SDG 2-AL2 and SDG 8; SDG 2-AL1a; and SDG 12 (Fig. 9). Although more dates will certainly change the details of the chronology of the SDG sites, current data shows human occupations in the Shuidonggou valley date to two broad periods: late Marine Isotope Stage 3 (MIS 3, c. 46-27 ka), and the early Holocene. Analyses of sediment grain size and pollen samples from SDG 2 demonstrate that a paleo-lake formed in the Shuidongou valley during late MIS 3. After the lake disappeared a desert steppe environment expanded into the valley (Gao et al. 2008; Liu et al. 2012). The first intensive occupation at Shuidonggou began between $46 \mathrm{ka}$ and $41 \mathrm{ka}$, and lasted until around $27 \mathrm{ka}$, during the presence of the paleo-lake. The late MIS 3 lake environment might have provided enough food resources and other affordances to attract human groups there on a regular basis. More arid environmental conditions, especially during the LGM made the Shuidonggou area less favorable, leading foragers to abandon the region. The Shuidonggou valley was reoccupied during the early Holocene at around $10.5 \mathrm{ka}$, shortly after the Younger Dryas.

Three broad lithic technological systems have been identified in the Shuidonggou area: macro-blade production, utilizing both Levallois and prismatic blade methods; unelaborated core and flake reduction sequences; and microblade production, mainly using wedge-shaped microblade cores (Fig. 10). As early as $46 \mathrm{ka}$, but probably around $42-41 \mathrm{ka}$, groups bearing the large-blade technology appeared in this valley. This technological system is best represented at SDG 1. AL7 of SDG 2 dates to 41.4-40.4 ka, although the material is limited to one large blade core. There are no reliable dates at SDG 9, but the blade assemblage is technologically similar to that of SDG 1. Several cores from SDG 7 show characteristics of Levallois blade production, but unfortunately their age and association with stratigraphy is uncertain. Some time between $41.8 \mathrm{ka}$ and $34.8 \mathrm{ka} \mathrm{sim}-$ ple core and flake technology appeared in the area, as documented by the small assemblages in AL6 and AL5b of SDG 2. At AL5a of SDG 2, blade production was present even though this layer is still undated and the archeological material is limited to one Levallois blade core. Beginning at $32.6 \mathrm{ka}$, relatively dense assemblages characterized by core and flake production and other types of cultural materials, including one freshwater shell bead fragment, were deposited at SDG 2 (AL3). During the period 31.2-28.8 ka, dense deposits of core and flake technology accumulated in AL2 of SDG 2 and in SDG 8. These occupations are accompanied by novel forms of material culture, including ostrich eggshell beads and bone tools. Other novel behavioral and technological features include soft-hammer percussion, importation of raw materials from comparatively distant sources, production of small bladelet-sized blanks, and production of wellmade endscrapers. The archaeological finds from SDG 7 can be attributed to the simple core and flake technology, although it is difficult to align this locality with the others because of the stratigraphic issues discussed above. At around 


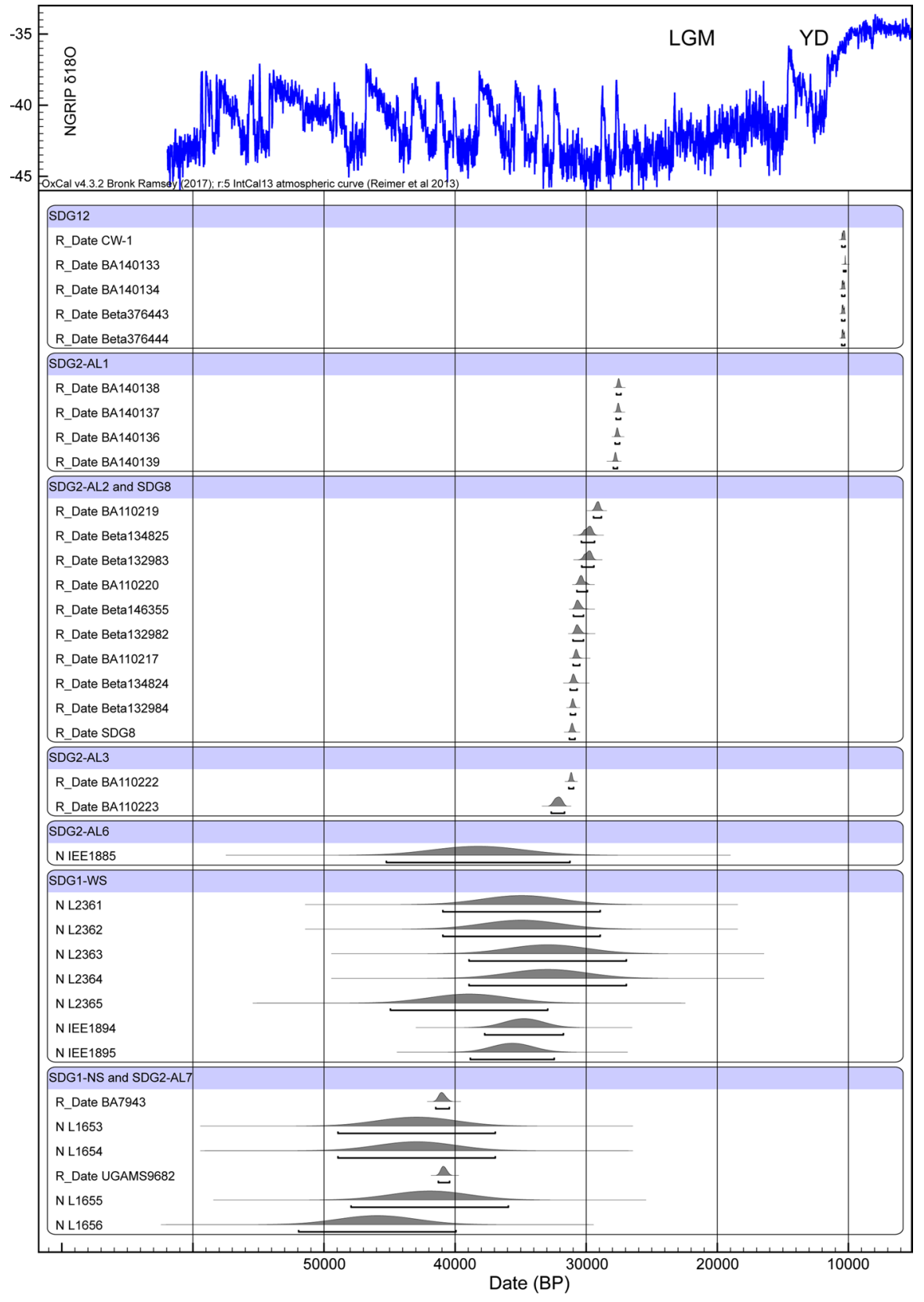

Fig. 9 Chronology of the Paleolithic layers at SDG sites. AMS dates are calibrated using OxCal4.2 software (Ramsey 2009) and INTCAL13 (Reimer et al. 2013). BP is before 1950, and all the OSL dates are converted according to their published dates 


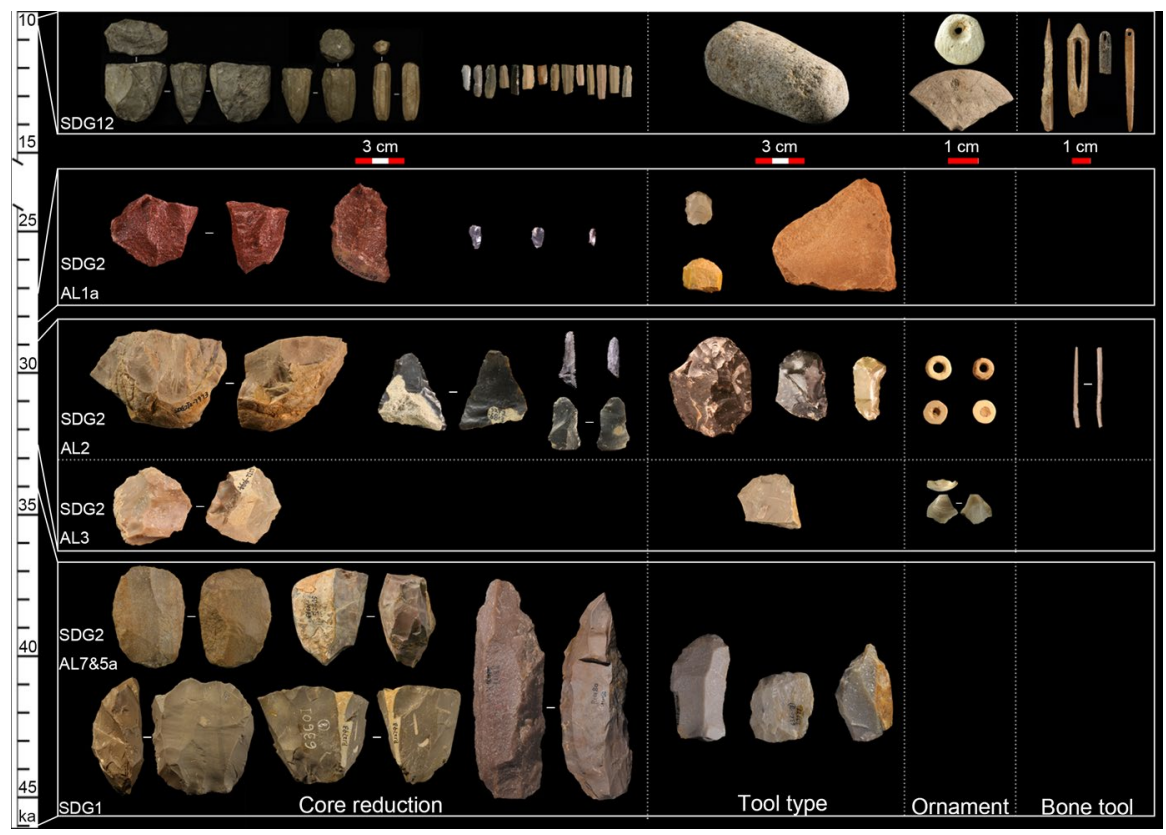

Fig. 10 The techno-typological sequence at the Shuidonggou sites

28.2-27.3 ka a core-flake assemblage with a large proportion of bipolar reduction yielding small elongated blanks was deposited at SDG 2 (AL1a); grinding tools with irregular overall shapes are also present. Finally, around 10.5-10.2 ka, after a long archaeological hiatus, a microblade assemblage with formal grinding tools, bone tools, and ornaments was deposited at SDG 12.

\section{Discussion and Conclusion}

Cultural and behavioral diversity are consistent features of the Upper Paleolithic globally. The timing and cultural characteristics of the period in China have not yet been worked out, but the archeological findings at the different Shuidonggou localities have demonstrated a relatively complex and discontinuous cultural sequence. The scarcity of blades and other tool types (endscrapers, burins) typical of the European Upper Paleolithic has encouraged scholars to use other kinds of material culture, such as ornaments and bone tools, to mark the onset of a new cultural stage in the Chinese Paleolithic sequence (Bar-Yosef and Wang 2012; Du et al. 2016; Qu, Bar-Yosef, Wang and $\mathrm{Wu}$ 2013). However, these materials are far from ubiquitous in the archaeological record from $45 \mathrm{ka}$ to $10 \mathrm{ka}$ in China (Li, Chen and Gao 2014; Qu et al. 2013; Wei et al. 2016; Zhang, Huang, Yuan, Fu and Zhou 2010). Because of their abundance, lithic artifacts have played and will continue to play an important role in describing Paleolithic cultural stages. The artifact assemblages from the Shuidonggou area contain three main technological components (outlined below) 
spanning the period of around 46-10 ka, forming a rough framework for the evolution of the Upper Paleolithic in North China (Figs. 9, 10).

1. Blade assemblages with both Levallois and prismatic methods were created around 46-33 ka at Shuidonggou. This signals the appearance of an early Upper Paleolithic with assemblage characteristics similar to those found in Western Eurasia. The distribution of this lithic industry was limited to the northern part of North China. Sites in Mongolia and the Siberian Altai contain similar lithic technology, and they are generally earlier (Derevianko 2011; Li, Kuhn et al. 2014; Li, Chen et al. 2016; Zwyns et al. 2014). For this reason, researchers have proposed that the macro-blade industry appeared in Shuidonggou as a result of technological diffusion (Brantingham et al. 2001; Peng, Wang and Gao 2014) or population dispersal from Mongolia and/or the Altai (Li, Kuhn et al. 2014; Li, Chen et al. 2016). Assemblages dominated exclusively by prismatic blade and bladelet production, typical of the later Upper Paleolithic in western Eurasia, have not yet been identified in the Shuidonggou area. But assemblages with prismatic blades, associated with the use of obsidian, have been identified at some sites in northeast China (Chen, Wang, Fang and Zhao 2006; Li, Chen et al. 2016). Unfortunately the northeast Chinese sites are not precisely dated, and the relationship between early UP and typical UP assemblages in northern China remains unknown.

2. Simple core and flake technology with specific technological innovations appeared in the SDG area at around $33 \mathrm{ka}$ and persisted until $27 \mathrm{ka}$. There may be hints of this kind of technology in earlier low-density, undated deposits at SDG 2 (AL5b and AL6). Simple core-flake assemblages had been present in North China since the early Pleistocene (Schick et al. 1991; Dennell 2008; Gao 2013; Wang 2005; Zhang 1990). They have usually been described as Mode 1 technology, following the scheme proposed by G. Clark (1969). Their persistence is often considered evidence of continuous evolution within the Chinese Paleolithic, perhaps even continuity from Homo erectus to Homo sapiens (e.g., Gao 2014; Wu and $\mathrm{Xu}$ 2016). Describing all core and flake assemblages in China as Mode 1 is highly problematic ( $\mathrm{Li} 2017$ ), but this subject is beyond the scope of this paper. Certainly the core and flake assemblage in AL2 of SDG2 (31-29 ka) shows various technological innovations when compared to earlier periods, including the use of softhammer percussion, importation of exotic raw material, systematic manufacture of small bladelet-sized blanks, and finely retouched endscrapers. Although not all technological innovations in AL2 of SDG 2 persisted into AL1, finely retouched endscrapers and small bladelet-sized blanks continued to be made, alongside new technological elements such as grinding tools. In the Shuidonggou area, this period ended at around $27 \mathrm{ka}$, although it might have persisted much later in other regions of northern China.

3. Microblade technology, a highly-evolved version of UP, appeared in the Shuidonggou area in the early Holocene, around $15 \mathrm{ka}$ later than in other regions of northern China, such as the Nihewan Basin, Henan, and Shanxi Province (Song et al. 2017, 2019; Wang and Qu 2014). Madsen et al. (2001) proposed a hypothesis based on the findings at SDG 2 that microblade technology originated from a combination of large blade technology and bipolar technology. Previous examina- 
tion of the bipolar products at SDG 2, especially the cores, did not demonstrate this evolutionary process (Li, Gao et al. 2013). Even though the detached products are similar in dimension, bipolar technology involved very different flaking procedures from microblade technology, which requires a systematic preparation of the platform and working surface and usually employs a pressure flaking technique (Kuzmin, Keates and Shen 2007). Moreover, the large chronological gap between the earlier blade assemblages (c. $40 \mathrm{ka}$ ) and the bipolar assemblages (c. $27 \mathrm{ka}$ ) at the SDG area undermines the contention that the large blade technology influenced bipolar technology. On balance, it is unlikely that microblade technology at Shuidonggou was derived from the earlier macro-blade technologies. Instead it is likely exogenous.

The origins of microblade technology have been debated for decades (Jia 1978; Kuzmin, Keates and Shen 2007; Song et al. 2019; Yi, Gao, Li and Chen 2016, and references therein). Siberia, Mongolia and north China are all candidates for its emergence, and two main hypotheses have been proposed: (a) microblade technology developed from prismatic blade assemblages such as have been found at UstKarakol in the Siberian Altai (e.g., Derevianko and Shunkov 2004; Keates 2007; Kuzmin 2007; Yi et al. 2016); or (b) it derived from core and flake assemblages such those known from the Xujiayao and Shiyu sites in North China (e.g., Jia 1978; Jia, Gai and You 1972). Because of the gap in occupation, the data from Shuidonggou cannot be used to support either hypothesis.

The terminology of the Upper Paleolithic in North China can be confusing, with divisions such as Initial Upper Paleolithic, Late Paleolithic, and so forth. The general term Upper Paleolithic (UP) usually describes archaeological materials found in western Eurasia with a group of specific cultural features. However, the material culture of North China in the period 45-10 ka differs from that in western Eurasia in terms of lithic technology and typology. The early blade assemblage for which Shuidonggou is best known has been included under the umbrella of Initial Upper Paleolithic (IUP). The term IUP was first applied to a specific assemblage from the site of Boker Tachtit (Level 4) and was subsequently extended to cover the earliest UP assemblages in the Levant with Levallois elements in blade production. Later, the designation IUP was extended to early UP assemblages from across Eurasia. The technological similarities of assemblages distributed from the Levant to northwest China could be a consequence of multiple processes, including migration, cultural transmission, and technological convergence, and the current definition of IUP has become too broad to be called a 'culture' in the usual sense (Kuhn and Zwyns 2014). So while the term IUP remains acceptable as a summary of the general technological features of the early blade assemblages from Shuidonggou, the precise historical relationship between the IUP assemblages of Shuidonggou and those of the rest of Eurasia has yet to be established.

The later core and flake assemblages from the Shuidonggou sites are clearly different from the west Eurasian Upper Paleolithic, as well as from assemblages dating to the Early and Middle Pleistocene in North China. Taking into account the unique lithic technological developments in North China, a two-stage model with Early and Late Paleolithic stages has been proposed (Ikawa-Smith 1978; Gao 1999; Gao and 
Norton 2002). Scholars formerly considered blades, ornaments, and bone tools to be the markers of the onset of the Late Paleolithic in China, just as in western Eurasia. However, those materials are not common in the Chinese Paleolithic record, and clearly some of them (such as blades) are intrusive. The core and flake assemblages with finely retouched endscrapers, ornaments and other technological innovations may well represent the onset of an indigenous Late Paleolithic in North China. If somehow microblade technology derived from the core and flake technology of North China, then the Late Paleolithic followed a totally different technological evolutionary trajectory from West Eurasia and Africa. Of course it is also possible, indeed likely, that advanced core and flake technology was replaced by exogenous microblade technology in North China. In this case it is important to explore the questions of when and how the core and flake assemblages were supplanted.

Identifying the makers of lithic assemblages is not an easy task, and often causes controversy, especially when stone tools and human fossils were not found together. Modern humans appeared in northern China around $40 \mathrm{ka}$ at Tianyuan Cave (Shang et al. 2007) and Zhoukoudian Upper Cave (Li, Bae et al. 2018), but the archaeological evidence from those sites is thin. No archaeological remains have been discovered at Tianyuan Cave, and a limited number of lithic artifacts (25 pieces) and ornaments (141 pieces) were unearthed at Upper Cave (Pei 1939). No modern human fossils were found in the Shuidonggou area or at other early UP sites in northern Asia. Therefore, the relationship of UP lithic technologies and modern humans in northern Asia remains unclear (Li, Chen et al. 2016). Nevertheless, scholars tend to believe that the Initial Upper Paleolithic in northern Asia was a product of modern humans (Gao, Wang and Guan 2013a; but see Bar-Yosef and Belfer-Cohen 2013). One piece of evidence used to support this is the presence of ornaments in the early UP sites, but the complex demographic situation in northern Asia leaves this hypothesis open to question. At Denisova Cave, a diversity of typical UP artifacts and ornaments was found in association with probably both Denisovans and Neanderthals (Douka et al. 2019; Krause et al. 2010; Reich et al. 2010; Prüfer et al. 2014; Slon et al. 2017), although this remains the only such case in northern Asia. Middle Paleolithic assemblages possibly made by Neandertals were recently reported at the Jinsitai Cave in northern China (Li, Kuhn et al. 2018), about a thousand kilometers northeast of the Shuidonggou sites. Different hominin groups may have co-existed widely during the period 50-30 ka in northern Asia. Clearly, establishing who was responsible for the Initial Upper Paleolithic in northern Asia requires more work. However, the wide distribution of the IUP provides much information with which to explore many intriguing topics related to human cultural evolution and demography during the Late Pleistocene in northern Asia.

The development of stone tool technologies in China is generally characterized as slow and incremental. This is especially true in southern China (Wang 1997, 2005). Changes in the nature of lithic production and artifact forms, though still relatively minor by western standards, are much more obvious in northern China. The presence of an apparently intrusive large-blade technology, indigenous coreflake technology, and microblade technology with likely exogenous origins complicates UP research in northern China. On the other hand, it provides a much more interesting scenario for examining cultural geography, human adaptation, population 
interactions, and demographic dynamics in the Late Pleistocene of East Asia. Exploration of other long archaeological sequences from different parts of northern China will help us better understand how the Upper Paleolithic in Late Pleistocene China coalesced and evolved.

Acknowledgements We are grateful to Timothy Taylor and the two anonymous reviewers, whose edits and comments made this a better paper. We would like to thank Prof. Hui-min Wang (Provincial Institute for Archaeology in Ningxia), Prof. Shu-wen Pei (IVPP, CAS), Dr. Chunxue Wang (Jilin University), Dr. Decheng Liu (RADI, CAS), Dr. Dong-wei Niu (Hebei Normal University) and Dr. Ming-jie Yi (Renmin University) for discussing issues at the Shuidonggou site. F. L. thanks the Alexander von Humboldt Foundation for the postdoctoral stipend and the Youth Innovation Promotion Association, CAS (2017102), and S. K. thanks the Chinese Academy of Sciences President's International Fellowship Initiative (Grant No. 2015VEA013) facilitating this study. This research was supported by the Strategic Priority Research Program of Chinese Academy of Sciences (Grant No. XDB26000000) and National Natural Science Foundation of China (Grant No. 41872028 and 41672024).

Open Access This article is distributed under the terms of the Creative Commons Attribution 4.0 International License (http://creativecommons.org/licenses/by/4.0/), which permits unrestricted use, distribution, and reproduction in any medium, provided you give appropriate credit to the original author(s) and the source, provide a link to the Creative Commons license, and indicate if changes were made.

\section{References}

Athreya, S., \& Wu, X.-Z. (2017). A multivariate assessment of the Dali hominin cranium from China: Morphological affinities and implications for Pleistocene evolution in East Asia. American Journal of Physical Anthropology, 164(4), 679-701.

Bar-Yosef, O. (1998). On the nature of transitions: The Middle to Upper Palaeolithic and the Neolithic revolution. Cambridge Archaeological Journal, 8(2), 141-163.

Bar-Yosef, O. (2002). The Upper Paleolithic revolution. Annual Review of Anthropology, 31, 363-393.

Bar-Yosef, O. (2006). Defining the Aurignacian. In O. Bar-Yosef \& J. Zilhão (Eds.), Towards a definition of the Aurignacian: Proceedings of the symposium held in Lisbon, Portugal, June 25-30, 2002. Trabalhos de Arqueologia (Vol. 45, pp. 11-18). Portugal: Trabalhos de Arqueologia.

Bar-Yosef, O., \& Belfer-Cohen, A. (2013). Following Pleistocene road signs of human dispersals across Eurasia. Quaternary International, 285, 30-43.

Bar-Yosef, O., \& Wang, Y.-P. (2012). Paleolithic archaeology in China. Annual Review of Anthropology, 41, 319-335.

Boëda, E., Hou, Y.-M., Forestier, H., Sarel, J., \& Wang, H.-M. (2013). Levallois and non-Levallois blade production at Shuidonggou in Ningxia, North China. Quaternary International, 295, 191-203.

Boule, M. H., Breuil, E., Licent, E., \& Teilhard de Chardin, P. (1928). Le Paléolithique de la Chine. Paris: Archives de l'Institut de Paléontologie Humaine.

Brantingham, P. J., Kaivoshapkin, A. I., Li, J.-Z., \& Tserendagva, Y. (2001). The initial Upper Paleolithic in northeast Asia. Current Anthropology, 42(5), 735-747.

Chen, Q.-J., Wang, C.-X., Fang, Q., \& Zhao, H.-L. (2006). Paleolithic artifacts from Shirengou site in 2004, Helong County, Yanbian City. Acta Anthropologica Sinica, 25(3), 106-114 (in Chinese with English abstract).

Chen, T.-M., Yang, Q., \& Wu, E. (1994). Antiquity of Homo sapiens in China. Nature, 368(6466), 55-56.

Chen, T.-M., Yuan, S.-X., \& Gao, S.-J. (1984). The study on Uranium-series dating of fossil bones and an absolute age sequence for the main Paleolithic sites of North China. Acta Anthropologica Sinica, 3(3), 259-269 (in Chinese with English abstract).

Clark, G. (1969). World prehistory: A new outline (2nd ed.). Cambridge: Cambridge University Press.

Conard, N. J. (2003). Palaeolithic ivory sculptures from southwestern Germany and the origins of figurative art. Nature, 426(6968), 830-832.

Dennell, R. (2008). The Palaeolithic settlement of Asia. Cambridge: Cambridge University Press. 
Derevianko, A. P. (2011). The Upper Paleolithic in Africa and Eurasia and the origin of Anatomically Modern Humans. Novosibirsk: Institute of Archaeology and Ethnography SB RAS.

Derevianko, A. P., \& Shunkov, M. V. (2004). Formation of the Upper Paleolithic traditions in the Altai. Archaeology, Ethnology, and Anthropology of Eurasia, 3(3), 12-40.

Douka, K., Slon, V., Jacobs, Z., Ramsey, C. B., Shunkov, M. S., Derevianko, A. P., et al. (2019). Age estimates for hominin fossils and the onset of the Upper Palaeolithic at Denisova Cave. Nature, 565(7741), 640-644.

Du, S.-S., Li, X., Zhou, L., Pang, H., Bar-Yosef, O., \& Wu, X.-H. (2016). Longquan Cave: An early Upper Palaeolithic site in Henan Province, China. Antiquity, 90(352), 876-893.

Gao, X. (1999). A discussion of the Chinese Middle Palaeolithic. Acta Anthropologica Sinica, 18(1), 1-16 (in Chinese with English abstract).

Gao, X. (2013). Paleolithic cultures in China: Uniqueness and divergence. Current Anthropology, 54(S8), $358-370$.

Gao, X. (2014). Archeological evidence for evolutionary continuity of Pleistocene humans in China and East Asia and related discussions. Acta Anthropologica Sinica, 33(3), 237-253 (in Chinese with English abstract).

Gao, X., \& Norton, C. J. (2002). A critique of the Chinese 'Middle Palaeolithic'. Antiquity, 76(292), 397-412.

Gao, X., Guan, Y., Chen, F.-Y., Yi, M.-J., Pei, S.-W., \& Wang, H.-M. (2014). The discovery of late Paleolithic boiling stones at SDG 12, North China. Quaternary International, 347, 91-96.

Gao, X., Pei, S.-W., Wang, H.-M., \& Zhong, K. (2004). A report on Paleolithic reconnaissance in Ningxia, North China. Acta Anthropologica Sinica, 23, 307-325 (in Chinese with English abstract).

Gao, X., Wang, H.-M., \& Guan, Y. (2013a). Research at Shuidongou: New advance and new perspective. Acta Anthropologica Sinica, 32(2), 121-132 (in Chinese with English abstract).

Gao, X., Wang, H.-M., Pei, S.-W., \& Chen, F.-Y. (2013b). Shuidonggou: Excavation and research report (2003-2007). Beijing: Science Press (in Chinese with English abstract).

Gao, X., Yuan, B.-Y., Pei, S.-W., Wang, H.-M., Chen, F.-Y., \& Feng, X.-W. (2008). Analysis of sedimentary-geomorphologic variation and the living environment of hominids at the Shuidonggou Paleolithic site. Chinese Science Bulletin, 53(13), 2025-2032.

Geng, K., \& Shan, P.-F. (1992). The Yinchuan area: Past, present, and future - Processes of Late Quaternary environmental evolution. Beijing: Cartographic Publishing House (in Chinese).

Graf, K. E. (2009). 'The good, the bad, and the ugly': Evaluating the radiocarbon chronology of the middle and late Upper Paleolithic in the Enisei River valley, south-central Siberia. Journal of Archaeological Science, 36(3), 694-707.

Guan, Y., Gao, X., Li, F., Pei, S.-W., Chen, F.-Y., \& Zhou, Z.-Y. (2012). Modern human behaviors during the late stage of the MIS 3 and the Broad Spectrum revolution: Evidence from a Shuidonggou Late Paleolithic site. Chinese Science Bulletin, 57(4), 379-386.

Guan, Y., Gao, X., Wang, H.-M., Chen, F.-Y., Pei, S.-W., Zhang, X.-L., et al. (2011). Spatial analysis of intra-site use at a Late Paleolithic site at Shuidonggou, northwest China. Chinese Science Bulletin, 56(32), 3457-3463.

Guan, Y., Pearsall, D. M., Gao, X., Chen, F.-Y., Pei, S.-W., \& Zhou, Z.-Y. (2014). Plant use activities during the Upper Paleolithic in East Eurasia: Evidence from the Shuidonggou site, northwest China. Quaternary International, 347, 74-83.

Habgood, P. J., \& Franklin, N. R. (2008). The revolution that didn't arrive: A review of Pleistocene Sahul. Journal of Human Evolution, 55(2), 187-222.

Ikawa-Smith, F. (1978). The early Paleolithic tradition of East Asia. In F. Ikawa-Smith (Ed.), Early Paleolithic in South and East Asia (pp. 1-10). Mouton: The Hague.

James, H. A., \& Petraglia, M. (2005). Modern human origins and the evolution of behavior in the later Pleistocene record of South Asia. Current Anthropology, 46(S5), S3-S27.

Jia, L.-P. (1978). Tradition, origin and distribution of Chinese microlith. Vertebrata Palasiatica, 16(2), 137-143 (in Chinese).

Jia, L.-P., Gai, P., \& Li, Y.-X. (1964). New materials from the Palaeolithic site of Shuidonggou. Vertebrata Palasiatica, 8(1), 75-86 (in Chinese).

Jia, L.-P., Gai, P., \& You, Y.-Z. (1972). Excavation report of the Paleolithic site of Shiyu, Shanxi. Chinese Journal of Archaeology, 1, 39-58 (in Chinese). 
Keates, S. G. (2007). Microblade technology in Siberia and neighboring regions: An overview. In Y. V. Kuzmin, S. G. Keates, \& C. Shen (Eds.), Origin and spread of microblade technology in northern Asia and North America (pp. 125-146). Burnaby: Archaeology Press of Simon Fraser University.

Keates, S. G., \& Kuzmin, Y. V. (2015). Shuidonggou localities 1 and 2 in northern China: Archaeology and chronology of the Initial Upper Palaeolithic in north-east Asia. Antiquity, 89(345), 714-720.

Klein, R. G. (2009). The human career: Human biological and cultural origins (3rd ed.). Chicago: University of Chicago Press.

Krause, J., Fu, Q., Good, J. M., Viola, B., Shunkov, M. V., Derevianko, A. P., et al. (2010). The complete mitochondrial DNA genome of an unknown hominin from southern Siberia. Nature, 464, 894-897.

Kuhn, S. L., \& Zwyns, N. (2014). Rethinking the Initial Upper Paleolithic. Quaternary International, 347, 29-38.

Kuzmin, Y. V. (2007). Geoarchaeological aspects of the origin and spread of micro-blade technology in northern and Central Asia. In Y. V. Kuzmin, S. G. Keates, \& C. Shen (Eds.), Origin and spread of microblade technology in northern Asia and North America (pp. 115-124). Burnaby: Archaeology Press of Simon Fraser University.

Kuzmin, Y. V., Keates, S. G., \& Shen, C. (Eds.). (2007). Origin and spread of microblade technology in northern Asia and North America. Burnaby: Archaeology Press of Simon Fraser University.

Li, F. (2017). Discussion on the G. Clark's technological models and its implication in Chinese Paleolithic. Archaeology, 9, 73-81 (in Chinese with English abstract).

Li, F., Bae, C. J., Ramsey, C. B., Chen, F., \& Gao, X. (2018a). Re-dating Zhoukoudian Upper Cave, northern China and its regional significance. Journal of Human Evolution, 121, 170-177.

Li, F., Chen, F.-Y., \& Gao, X. (2014a). 'Modern behaviors' of ancient populations at Shuidonggou Locality 2 and their implications. Quaternary International, 347, 66-73.

Li, F., Chen, F.-Y., Wang, Y.-H., \& Gao, X. (2016a). Technology diffusion and population migration reflected in blade techniques in northern China in the Late Pleistocene. Science China Earth Sciences, 59(8), 1-14.

Li, F., \& Gao, X. (2018). The origins of modern Homo sapiens in China: An archaeological perspective. Acta Anthropologica Sinica, 37(2), 176-191 (in Chinese with English abstract).

Li, F., Gao, X., Chen, F.-Y., Pei, S.-W., Zhang, Y., Zhang, X.-L., et al. (2013a). The development of Upper Palaeolithic China: New results from the Shuidonggou site. Antiquity, 87(336), 368-383.

Li, F., Kuhn, S. L., Chen, F.-Y., \& Gao, X. (2016b). Raw material economies and mobility patterns in the Late Paleolithic at Shuidonggou locality 2, North China. Journal of Anthropological Archaeology, 43, 83-93.

Li, F., Kuhn, S. L., Chen, F., Wang, Y., Southon, J., Peng, F., et al. (2018b). The easternmost Middle Paleolithic (Mousterian) from Jinsitai Cave, North China. Journal of Human Evolution, 114, 76-84.

Li, F., Kuhn, S. L., \& Gao, X. (2015). A response to Keates and Kuzmin. Antiquity, 89(345), 721-723.

Li, F., Kuhn, S. L., Gao, X., \& Chen, F.-Y. (2013b). Re-examination of the dates of large blade technology in China: A comparison of Shuidonggou Locality 1 and Locality 2. Journal of Human Evolution, 64(2), 161-168.

Li, F., Kuhn, S. L., Olsen, J. W., Chen, F.-Y., \& Gao, X. (2014b). Disparate Stone Age technological evolution in North China: Lithic technological variability and relations between populations during MIS 3. Journal of Anthropological Research, 70(1), 35-67.

Li, X. G., Liu, G. L., Xu, G. Y., Li, F. C., Wang, F. L., \& Liu, K. S. (1987). Dating reports on the ${ }^{14}$ C dating methodology (PV). In Radiocarbon Dating Society of Chinese Quaternary Research Association (Ed.), Contribution to the Quaternary glaciology and geology (4, pp. 16-38). Beijing: Geological Publishing House (in Chinese).

Li, Z.-Y., Wu, X.-J., Zhou, L.-P., Wu, L., Gao, X., Nian, X.-M., et al. (2017). Late Pleistocene archaic human crania from Xuchang, China. Science, 355(6328), 969-972.

Licent, E., \& Teilhard de Chardin, P. (1925). Le Paléolithique de la Chine. L'Anthropologie, 35, 201-234.

Lin, S., Peng, F., Zwyns, N., Guo, J.-L., Wang, H.-M., \& Gao, X. (2018). Detecting patterns of local raw material utilization among informal lithic assemblages at the late Paleolithic site of Shuidonggou Locality 2 (China). Archaeological Research in Asia. https://doi.org/10.1016/j.ara.2018.11.003.

Liu, D.-C. (2008). A comparison study of human survival environment in Zhijidong and Shuidonggou areas during MIS 3. Ph.D. Dissertation submitted to Peking University.

Liu, D.-C., Chen, F.-Y., Zhang, X.-L., Pei, S.-W., Gao, X., \& Xia, Z.-K. (2008). Preliminary comments on the paleoenvironment of the Shuidonggou Locality 12. Acta Anthropologica Sinica, 27(4), 295303 (in Chinese with English abstract). 
Liu, D.-C., Gao, X., Liu, E.-F., Pei, S.-W., Chen, F.-Y., \& Zhang, S.-Q. (2012). The depositional environment at Shuidonggou Locality 2 in northwest China at 72-18 ka BP. Acta Geologica Sinica, 86(6), 1539-1546.

Liu, D.-C., Wang, X.-L., Gao, X., Xia, Z.-K., Pei, S.-W., Chen, F.-Y., et al. (2009). Progress in the stratigraphy and geochronology of the Shuidonggou site, Ningxia, North China. Chinese Science Bulletin, 54(21), 3880-3886.

Madsen, D. B., Li, J.-Z., Brantingham, P. J., Gao, X., Elston, R. G., \& Bettinger, R. L. (2001). Dating Shuidonggou and the Upper Palaeolithic blade industry in North China. Antiquity, 75(290), $706-716$.

Martí, A. P., Wei, Y., Gao, X., Chen, F.-Y., \& d'Errico, F. (2017). The earliest evidence of coloured ornaments in China: The ochred ostrich eggshell beads from Shuidonggou Locality 2. Journal of Anthropological Archaeology, 48, 102-113.

Morgan, C., Barton, L., Yi, M.-J., Bettinger, R. L., Gao, X., \& Peng, F. (2014). Redating Shuidonggou Locality 1 and implications for the Initial Upper Paleolithic in East Asia. Radiocarbon, 56(1), $165-179$.

Nian, X.-M., Gao, X., \& Zhou, L.-P. (2014). Chronological studies of Shuidonggou (SDG) Locality 1 and their significance for archaeology. Quaternary International, 347, 5-11.

Ningxia Museum, Ningxia Bureau of Geology, Chu Cheng Geological Research Team. (1987). A report on the 1980 excavation at Shuidonggou. Chinese Journal of Archaeology, 4, 439-449 (in Chinese).

Niu, D.-W. (2014). Site formation processes and lithic technology: An archaeological study on the Shuidonggou Locality 7, North China. Ph.D. Dissertation submitted to Unversity of Chinese Academy of Sciences (in Chinese with English abstract).

Niu, D.-W., Pei, S.-W., Zhang, S.-Q., Zhou, Z.-Y., Wang, H.-M., \& Gao, X. (2016). The Initial Upper Palaeolithic in northwest China: New evidence of cultural variability and change from Shuidonggou Locality 7. Quaternary International, 400, 111-119.

Pei, W.-C. (1939). On the Upper Cave industry. Palaeontologica Sinica, 9, 1-59.

Pei, S.-W., Gao, X., Wang, H.-M., Kuman, K., Bae, C. J., Chen, F.-Y., et al. (2012). The Shuidonggou site complex: New excavations and implications for the earliest Late Paleolithic in North China. Journal of Archaeological Science, 39(12), 3610-3626.

Pei, S.-W., Niu, D.-W., Guan, Y., Nian, X.-M., Kuman, K., Bae, C. J., et al. (2014). The earliest Late Paleolithic in North China: Site formation processes at Shuidonggou Locality 7. Quaternary International, 347, 122-132.

Peng, F., Guo, J.-L., Lin, S. C., Wang, H.-M., \& Gao, X. (2018). The onset of Late Paleolithic in North China: An integrative review of the Shuidonggou site complex, China. L'Anthropologie, 122(1), 74-86.

Peng, F., Lin, S. C., Guo, J.-L., Wang, H.-M., \& Gao, X. (2017). The application of SfM photogrammetry software for extracting artifact provenience from Palaeolithic excavation surfaces. Journal of Field Archaeology, 42(4), 326-336.

Peng, F., Wang, H.-M., \& Gao, X. (2014). Blade production of Shuidonggou Locality 1 (northwest China): A technological perspective. Quaternary International, 347, 12-20.

Petraglia, M. D., Haslam, M., Fuller, D. Q., Boivin, N., \& Clarkson, C. (2010). Out of Africa: New hypotheses and evidence for the dispersal of Homo sapiens along the Indian Ocean rim. Annals of Human Biology, 37(3), 288-311.

Pettitt, P. B., Davies, W., Gamble, C. S., \& Richards, M. B. (2003). Palaeolithic radiocarbon chronology: Quantifying our confidence beyond two half-lives. Journal of Archaeological Science, 30(12), 1685-1693.

Prüfer, K., Racimo, F., Patterson, N., Jay, F., Sankararaman, S., Sawyer, S., et al. (2014). The complete genome sequence of a Neanderthal from the Altai Mountains. Nature, 505(7481), 43-49.

Qu, T.-L., Bar-Yosef, O., Wang, Y.-P., \& Wu, X.-H. (2013). The Chinese Upper Paleolithic: Geography, chronology, and techno-typology. Journal of Archaeological Research, 21(1), 1-73.

Ramsey, C. B. (2009). Bayesian analysis of radiocarbon dates. Radiocarbon, 51(1), 337-360.

Reich, D., Green, R. E., Kircher, M., Krause, J., Patterson, N., Durand, E. Y., et al. (2010). Genetic history of an archaic hominin group from Denisova Cave in Siberia. Nature, 468(7327), 1053-1060.

Reimer, P. J., Bard, E., Bayliss, A., Beck, J. W., Blackwell, P. G., Ramsey, C. B., et al. (2013). IntCal13 and Marine13 radiocarbon age calibration curves 0-50,000 years cal BP. Radiocarbon, 55(4(intcal 13)), 1869-1887.

Schick, K., Toth, N., Wei, Q., Clark, J. D., \& Etler, D. (1991). Archaeological perspectives in the Nihewan Basin, China. Journal of Human Evolution, 21(1), 13-26. 
Shang, H., Tong, H.-W., Zhang, S.-Q., Chen, F.-Y., \& Trinkaus, E. (2007). An early modern human from Tianyuan cave, Zhoukoudian, China. Proceedings of the National Academy of Sciences of the United States of America, 104(16), 6573-6578.

Slon, V., Hopfe, C., Weiß, C. L., Mafessoni, F., de la Rasilla, M., Lalueza-Fox, C., et al. (2017). Neandertal and Denisovan DNA from Pleistocene sediments. Science, 356(6338), 605-608.

Song, Y.-H., Cohen, D. J., Shi, J.-M., Wu, X.-H., Kvavadze, E., Goldberg, P., et al. (2017). Environmental reconstruction and dating of Shizitan 29, Shanxi Province: An early microblade site in North China. Journal of Archaeological Science, 79, 19-35.

Song, Y.-H., Grimaldi, S., Santaniello, F., Cohen, D. J., Shi, J.-M., \& Bar-Yosef, O. (2019). Re-thinking the evolution of microblade technology in East Asia: Techno-functional understanding of the lithic assemblage from Shizitan 29 (Shanxi, China). PLOS ONE, 14(2), e0212643.

Wang, C.-X., Feng, X.-W., Wang, H.-M., Pei, S.-W., Chen, F.-Y., Zhang, X.-L., et al. (2015). A preliminary report on excavation at Shuidonggou Locality 8 in Ningxia Hui Autonomous Region, North China. Acta Anthropologica Sinica, 34(4), 478-491 (in Chinese with English abstract).

Wang, H.-M., Pei, S.-W., Ma, X.-L., \& Feng, X.-W. (2007). A preliminary report on the excavations of Shuidonggou localities 3, 4, 5 in Ningxia. Acta Anthropologica Sinica, 26(3), 206-221 (in Chinese with English abstract).

Wang, Y.-P. (1997). Pleistocene environment and the development of Paleolithic in South China. Beijing: Peking University Press (in Chinese).

Wang, Y.-P. (2005). Roots of Pleistocene hominids and cultures in China. Aurora Centre for the Study of Ancient Civilizations, Peking University Publication Series No. 11. Beijing: Science Press (in Chinese).

Wang, Y.-P., \& Qu, T.-L. (2014). New evidence and perspectives on the Upper Paleolithic of the Central Plain in China. Quaternary International, 347, 176-182.

Wei, Y., d'Errico, F., Vanhaeren, M., Li, F., \& Gao, X. (2016). An early instance of Upper Palaeolithic personal ornamentation from China: The freshwater shell bead from Shuidonggou 2. PLoS ONE, $11, \mathrm{e} 0155847$.

Wu, X.-Z., \& Athreya, S. (2013). A description of the geological context, discrete traits, and linear morphometrics of the Middle Pleistocene hominin from Dali, Shaanxi Province, China. American Journal of Physical Anthropology, 150(1), 141-157.

$\mathrm{Wu}, \mathrm{X} .-\mathrm{Z} ., \mathrm{Xu}$, X. (2016). The origin of modern humans in China viewed from the Paleolithic data and Daoxian human fossils. Acta Anthropologica Sinica, 35(1), 1-13 (in Chinese with English abstract).

Yi, M.-J., Barton, L., Morgan, C., Liu, D.-C., Chen, F.-Y., Zhang, Y., et al. (2013). Microblade technology and the rise of serial specialists in north-central China. Journal of Anthropological Archaeology, 32(2), 212-223.

Yi, M.-J., Bettinger, R. L., Chen, F.-Y., Pei, S.-W., \& Gao, X. (2014). The significance of Shuidonggou Locality 12 to studies of hunter-gatherer adaptive strategies in North China during the Late Pleistocene. Quaternary International, 347, 97-104.

Yi, M.-J., Gao, X., Li, F., \& Chen, F.-Y. (2016). Rethinking the origin of microblade technology: A chronological and ecological perspective. Quaternary International, 400, 130-139.

Yi, M.-J., Gao, X., Wang, H.-M., Pei, S.-W., \& Chen, F.-Y. (2015). A study on cores unearthed from the Shuidonggou Locality 12 in 2007. Acta Anthropologica Sinica, 34(2), 166-179 (in Chinese with English abstract).

Zhang, J.-F., Huang, W.-W., Yuan, B.-Y., Fu, R.-Y., \& Zhou, L.-P. (2010). Optically stimulated luminescence dating of cave deposits at the Xiaogushan prehistoric site, northeastern China. Journal of Human Evolution, 59(5), 514-524.

Zhang, S.-S. (1990). Regional industrial gradual advance and cultural exchange of Paleolithic in North China. Acta Anthropologica Sinica, 9(4), 322-333 (in Chinese with English abstract).

Zhang, S.-S. (1999). A study of stone artefacts found at the Xiaokouzi prehistoric site. Acta Anthropologica Sinica, 18(2), 81-100 (in Chinese with English abstract).

Zhang, S.-Q., Doyon, L., Zhang, Y., Gao, X., Chen, F.-Y., Guan, Y., et al. (2018). Innovation in bone technology and artefact types in the late Upper Palaeolithic of China: Insights from Shuidonggou Locality 12. Journal of Archaeological Science, 93, 82-93.

Zhang, Y., Gao, X., Pei, S.-W., Chen, F.-Y., Niu, D.-W., Xu, X., et al. (2016). The bone needles from Shuidonggou Locality 12 and implications for human subsistence behaviors in North China. Quaternary International, 400, 149-157. 
Zwyns, N., Gladyshev, S. A., Gunchinsuren, B., Bolorbat, T., Flas, D., Dogandžić, T., et al. (2014). The open-air site of Tolbor 16 (northern Mongolia): Preliminary results and perspectives. Quaternary International, 347, 53-65.

Publisher's Note Springer Nature remains neutral with regard to jurisdictional claims in published maps and institutional affiliations.

\section{Affiliations}

\section{Feng $\mathrm{Li}^{1,2,3}$ (D) Steven L. Kuhn ${ }^{4} \cdot$ Ofer Bar-Yosef ${ }^{5} \cdot$ Fu-you Chen ${ }^{1,2} \cdot$ Fei Peng $^{1,2}$. Xing $\mathrm{Gao}^{1,2,6}$}

1 Key Laboratory of Vertebrate Evolution and Human Origins of Chinese Academy of Sciences, Institute of Vertebrate Paleontology and Paleoanthropology, Chinese Academy of Sciences, 142 Xizhimenwai Street, Beijing 100044, China

2 CAS Center for Excellence in Life and Paleoenvironment, Beijing 100044, China

3 Department of Early Prehistory and Quaternary Ecology, University of Tübingen, Tübingen 72070, Germany

4 Department of Anthropology, University of Arizona, Bldg. 30, Tucson, AZ 85721-0030, USA

5 Department of Anthropology, Harvard University, Cambridge, MA 02138, USA

6 University of Chinese Academy of Sciences, Beijing 100049, China 